\title{
AN INVESTIGATION OF THE ELECTRIC INTENSITIES AND ELECTRIC DISPLACEMENT PRODUCED IN IN- SULATORS BY THEIR MOTION IN A MAGNETIC FIELD. ${ }^{\prime}$
}

\author{
By S. J. BARNetT.
}

INTRODUCTION.

FROM the classical experiments of Ampère and Rowland it follows that an electrified particle with charge $q$ moving with velocity $v$ in a magnetic field at a point where the induction is $B$ is acted upon by a force $F$ equal, if suitable units are used, to the product of the charge $q$ by the vector product of the velocity $v$ and the induction $B$. That is,

$$
F=q V v B
$$

Hence if ether or matter is electrically constituted and moves in a magnetic field, each moving electrified constituent is acted upon by an electromagnetic force in accordance with (I); that is, the moving substance is the seat of an intrinsic electric intensity $f$, the " motional intensity" of Mr. Heaviside, given by the equation

$$
f=F / q=V v B \text {. }
$$

The relative displacement of the oppositely electrified constituents of the moving substances produced by the motional intensity $f$ gives rise to an electric field; and the intensity $E$ of this field acts on all dielectrics which the field contains, whether at rest or in motion. If both ether and matter move, both intensities act on both substances. But if the ether remains fixed and the matter moves through it, the intensity $f$ acts on the matter only, while the field intensity $E$ acts on both the ether and the matter. The actual electric displacement, if the matter is insulating, depends only on

1 Presented in part to the American Physical Society, October 19, 1907.

The paper describes also some observations on an electrical effect produced in certain cases by rotation in a region not a magnetic field. 
both intensities and on the dielectric constants of the matter and the ether. If the medium is conducting, much simplification arises when the current density is zero. If the current density is not zero, other considerations must be introduced.

The existence of the motional intensity in conductors was discovered by Faraday in I $83 \mathrm{I}$, and the subject has been studied in detail by him and many others. The results of all experiments which have been made upon the subject are in accord with the theory given in equation (2).

The first experiments on the motional intensity and displacement in insulators were published by Blondlot ${ }^{1}$ early in I902. In these experiments a stream of dust-free air was passed with a variable velocity between the rectangular pole-faces $N S$ of a magnet and two rectangular brass plates $A B$ and $C D$ arranged as shown in Figs. I

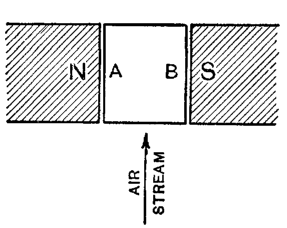

Fig. 1.

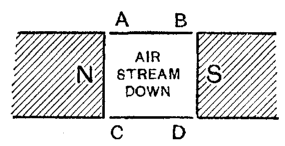

Fig. 2.

and 2. The velocity of the air was parallel to the pole-faces and the plates, and perpendicular to the lines of magnetic intensity stretching through the central part of the field. When the velocity of the air was a maximum the plates $A B$ and $C D$ were connected together metallically for an instant. Then one of the plates was removed and tested for charge. The charge to be expected on the hypothesis that the ether moves with the matter was many times greater than the smallest charge that could be detected; while the charge to be expected on the hypothesis that the ether remains fixed while the matter moves through it was far less than the smallest charge that could be detected. In the experiments no charge was detected. Thus the investigation confirmed the theory of Lorentz, according to which the ether is fixed.

The only other investigation hitherto published on the subject is

${ }^{1}$ Journal de Physique, January, 1902. 
that of $\mathrm{H}$. A. Wilson, ${ }^{1}$ who made experiments on ebonite in 1903 and I904. These experiments also, which will be further discussed below, support the theory of Lorentz.

The investigation described here was begun, in a way, in I902, when a piece of apparatus was designed and partially constructed. Lack of funds, however, put an early end to the work. Its continuance was made possible by a grant received from the Carnegie Institution early in 1904. The design of apparatus submitted to the $i^{n s t i t u t i o n ~ w a s ~ t h e n ~ g o n e ~ o v e r ~ c a r e f u l l y ~ a n d ~ v e r y ~ g r e a t l y ~ i m p r o v e d, ~}$ though no experimental work was practicable until near the summer of I906. In the meantime, experience in another investigation, not yet completed, together with some serious troubles which Dr. Wilson's method of experiment gave him, convinced me of the very great difficulties involved in low voltage electrostatic work when insulated slipping contacts are used, and when insulators or insulated conductors move in air not free from dust. To eliminate these difficulties and to secure other important advantages, the apparatus used in the investigation as finally carried out was constructed on lines quite different from those proposed to the Carnegie Institution. In some important respects it resembles the apparatus used by Wilson, while in many others it differs greatly therefrom.

\section{Method and Theory.}

A diagram of the principal pieces of apparatus used in the electrostatic part of the experiment proper is given in Fig. 3. In order to save space later the description given here is more complete than would otherwise be advisable. The insulator under investigation has the form of a hollow circular cylinder $A$ fitted closely on a coaxial rotor $B$ of bronze. This rotor revolves centrally and symmetrically within a large cylindrical coil $C$ of copper wire wound on a brass bobbin $D$. The magnetic field is produced by a current in this coil. The bearings $E E$ in which the rotor $B$ moves are screwed to the flanges forming the ends of the bobbin $D$. The cylinder $A$ is covered with a thin conducting coat $F$. A little longer than $A$, and surrounding it coaxially, is a uniform brass tube $G$. Surrounding this are the coaxial brass tubes $H$ and $D$, the latter a part of the

\footnotetext{
${ }^{1}$ Roy. Soc. Phil. Trans., Series A, September, I904.
} 
bobbin, and both together forming, with the brass rings soldered between them near the ends, a jacket for water or air. The tube $G$ is insulated from $H$ by small blocks of amber. Between these two tubes is a brass rod $J J$ capable of being rotated in the brass bearings

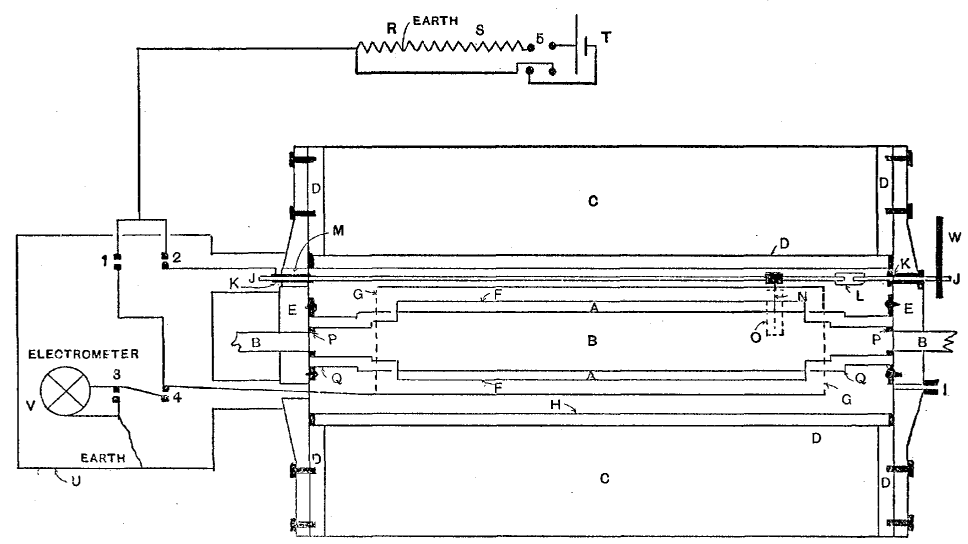

Fig. 3.

$K K$ near its ends. The rod is cut near its $\mathrm{S}$. end and the two parts are separated by a block of amber $L$. At the $N$. end the bearing $K$ is surrounded by an amber block $M$, which insulates it from the bobbin. Screwed to the insulated, or N., part of the $\operatorname{rod} J J$ is a stiff curved brass wire $N$ by which this part of the rod may be brought into contact with the metal coat of $A$ without touching the tube $G$. For this purpose a small slit $O$ is cut in $G$. Small ebonite rings $P P$ make the electrical contacts between the rotor $B$ and the bearings always nearly the same. Brass tubes $Q Q$, of very nearly the same diameter near the rotor as that of the part of the rotor within $A$, and coaxial with $A$, extend from the bearings $E E$ almost into contact with $B$, and form electric screens. A potentiometer $R S$ and battery $T$, with commutator 5 , produces the voltage (along $R$ ) used for standardization purposes. An electrometer $V$ is the principal measuring instrument. Potentiometer and electrometer connections with $J$ and $G$ are made by amber keys I, 2, 3, 4, of special design described below. Except as shown in the figures, the space holding the electrometer and its connections is practically metal enclosed. The metal case is earthed. 
When the coil $C$ is traversed by an electric current, the region occupied by the bronze rotor, the insulating cylinder, and its metal coat, becomes a magnetic field, in the central part of which the lines of intensity are parallel to the axis of the rotor. In the rest of this region there is a component of the intensity in this direction. Hence, by (2), when the rotor is revolved, a motional electric intensity is developed in the moving bodies, radial in the central portions and with a radial component elsewhere. If the motional intensity is directed outward, the intensity of the resulting electric field will be directed inward in the moving insulator and conductors, and it will be directed outward in the air between the tubes $F$ and $G$, which is supposed to be earthed, since the voltage from any point $P$ of $F$ to $G$ is the same as that from $P$ to the earthed bearings through $F$, the insulator, and the bronze rotor. We proceed to the calculation of the mean potential of the outer surface of $F$. When the value of this quantity on any theory has been determined, an experimental method can be devised for testing the validity of this theory.

Potential of $F$, Ideal Case.

Consider first, for simplicity, the ideal case in which the magnetic field is uniform throughout the entire length of the moving parts; the insulator $A$ so long that sensibly all the lines of intensity in the electric fields are radial, the end effects being entirely neglible; the rotor, an infinitely thin tube, of the same diameter throughout, and its surface everywhere at zero potential, and the thickness of the conducting tube $F$ neglible. The number of revolutions made by the rotor per second will be denoted by $n$.

The ether will at first be assumed to remain fixed. The motional intensity within the insulator at a distance $r$ from the axis is

$$
f=V v B=2 \pi r n B
$$

in magnitude, and will be considered positive when directed outward. If the electric field intensity at the same distance from the axis in the resulting field is denoted by $E$, considered positive when directed outward, the total electric intensity acting on the matter, not including the ether, is $f+E$, and the electric displacement in the matter alone is

$$
D=(K-\mathrm{I})(f+E),
$$


$K$ being the dielectric constant of the matter including the ether, and I being the dielectric constant of the ether.

The outward electric flux in the insulator, due to this displacement, across a cylinder of radius $r$ coaxial with $A$ and of the same length $l$, is

$$
D \cdot 2 \pi r l=(K-\mathrm{I})(f+E) 2 \pi r l ;
$$

and this is equal to the electric flux back through the ether within $A$ together with that from the outer surface of $A$ to the earthed conductors, the total charge upon $F$, which is insulated, being zero.

Let the capacity which the condenser $A B F$ would have if its dielectric were ether only and its field wholly confined to the region occupied by the dielectric $A$ be denoted by $S$; the capacity of the part of the field whose tubes of displacement stretch between $F$ (and its connections, if any) and $G$ (which is earthed), by $S^{\prime}$; and the voltage from the cylinder $F$ to the rotor $B$, or the potential of $F$, by $V$. Then we have, from the last paragraph,

$$
(K-\mathrm{I})(f+E) 2 \pi r l=4 \pi\left(S V+S^{\prime} V\right)=4 \pi\left(S+S^{\prime}\right) V,
$$

and therefore also

$$
f=\frac{2\left(S+S^{\prime}\right) V}{(K-\mathrm{I}) l r}-E
$$

The motional E.M.F. $\Psi$ from $B$ to $F$ through the cylinder $A$, with internal and external radii $r_{1}$ and $r_{2}$, is thus

$$
\begin{aligned}
\Psi & =\int_{r_{1}}^{r_{2}} f d r=\frac{2\left(S+S^{\prime}\right) V}{(K-\mathrm{I}) l} \int_{r_{1}}^{r_{2}} \frac{d r}{r}-\int_{r_{1}}^{r_{2}} E d r \\
& =V\left[\frac{S+S^{\prime}}{K-\mathrm{I}} \cdot \frac{\mathrm{I}}{\frac{l}{2 \log r_{2} / r_{1}}}+\mathrm{I}\right]=V\left[\frac{S+S^{\prime}}{(K-\mathrm{I}) S}+\mathrm{I}\right] .
\end{aligned}
$$

We have also

$$
\Psi=\int_{r_{1}}^{r_{2}} f d r=2 \pi n B \int_{r_{1}}^{r_{2}} r d r=n B\left(\pi r_{2}^{2}-\pi r_{1}^{2}\right),
$$

i. e., the rate at which magnetic flux is cut by any line fixed in the dielectric and extending from $B$ to $F$. The sign of $\Psi$ is the same as that of $f$ or $V v B$. 
Equation (3) may be written

$$
V=\Psi \frac{(K-\mathrm{I}) S}{K S+S^{\prime}}
$$

And, if $S^{\prime \prime}$ is written for $K S$, the actual capacity of the condenser $A B F$ when its field is confined entirely to the dielectric $A$, this becomes

$$
V=\Psi \frac{(K-1) S^{\prime \prime}}{K\left(S^{\prime \prime}+S^{\prime}\right)}
$$

If the ether is not at rest, but moves with the same velocity as that of the matter it permeates, we must write $K$ in place of $K-\mathrm{I}$, and remove $S$, in (3) and the preceding equations. We thus obtain, on this hypothesis,

$$
V=\Psi \frac{S^{\prime \prime}}{S^{\prime \prime}+S^{\prime}}
$$

Also, if $A$ were a conductor, instead of an insulator, we should have $K=\infty$, and therefore

$$
V=\Psi \frac{S^{\prime \prime}}{S^{\prime \prime}+S^{\prime}}
$$

as in (7). Thus the same expression is obtained in the case of a conductor whether the ether is at rest or in motion.

The Electric Field Within the Insulating Cylinder.

This field will be discussed here for two interesting cases only, viz., (I) that in which the metal tube $F$ either does not exist or is disconnected from all other conductors, and (2) that in which the tube $F$ is connected with the rotor $B$ by a wire at rest, so that the voltage between $F$ and $B$ is zero. In both cases $f$ and $E$ will be considered positive when directed radially outward.

In case I, the total displacement $D$ at all points of a cylinder of radius $r>r_{1}<r_{2}$, coaxial with $A$, is, if the ether is at rest,

$$
D=(K-\mathrm{I}) f+K E=K E+(K-\mathrm{I}) \omega r B=0,
$$

where $\omega=2 \pi n$; so that

$$
E=-\frac{K-\mathrm{I}}{K} f=-\frac{\dot{K}-\mathrm{I}}{K} \omega B r
$$


Within the hollow rotor and outside the tube $F$ or the external surface of the dielectric $A$, there is no intensity.

When $F$ and $B$ are connected by a conductor, as in case 2, all the lines of field intensity traversing the whole distance between $B$ and $F$ disappear, the voltage being reduced to zero. But the field intensity does not vanish except over one cylinder of radius $r_{0}$ to be determined. If it did, the charge on the tube $F$ would be greater than the opposite charge on the rotor $B$, and the dielectric itself would be internally charged, since $f$ increases proportionally with $r$, and $D$ would therefore increase in the same way. The voltage through $A$ being zero, the direction of the field intensity, always radial, changes in sign at the cylinder of radius $r_{0}$. Within this cylinder $E$ has the same direction as $f$, so as to increase the total displacement; while outside this cylinder it has the opposite direction, so as to decrease the displacement which would exist were $f$ alone acting. Over the cylinder of radius $r_{0}$ the field intensity vanishes. In this way the voltage between $B$ and $F$ is kept zero, and the electric flux across all cylinders which can be drawn between $B$ and $F$ is kept constant and equal to that across the cylinder of radius $r_{0}$. E, $r_{0}$, and $q$, the charge per unit length upon $B$, can be determined as follows:

The outward electric flux across unit length of a cylinder of radius $r$ is

$$
4 \pi q=[(K-\mathrm{I}) f+K E] 2 \pi r=[(K-\mathrm{I}) \omega B r+K E] 2 \pi r .
$$

If we put $r=r_{0}$, and therefore $E=0$, this equation becomes

$$
4 \pi q=(K-\mathrm{I}) \omega B \cdot 2 \pi r_{0}^{2} .
$$

From these equations

$$
E=\frac{K-\mathrm{I}}{K}-\frac{\omega B}{r}\left(r_{0}^{2}-r^{2}\right)
$$

The radius $r_{0}$ can be obtained from (II) and the consideration that the voltage between $B$ and $F$ is zero. Thus

or

$$
\mathrm{O}=\int_{r_{1}}^{r_{2}} E d r=\frac{K-\mathrm{I}}{K} \omega B \int_{r_{1}}^{r_{2}}\left(\frac{r_{0}^{2}}{r}-r\right) d r
$$

$$
r_{0}^{2} \log \frac{r_{2}}{r_{1}}-\frac{1}{2}\left(r_{2}^{2}-r_{1}^{2}\right)=0
$$


whence

$$
r_{0}=\left(\frac{r_{2}^{2}-r_{1}^{2}}{2 \log r_{2} / r_{1}}\right)^{\frac{1}{2}}
$$

If the ether moves with the matter, $K-\mathrm{I}$ must be replaced by $K$

Mean Potential of $F$, Actual Case.

In the actual case the magnetic field is not uniform throughout the rotating parts of the apparatus, the cylinder $F$ is not of neglible thickness, the cylinders may not be so long that the end effects can be entirely neglected, and their diameters are not perfectly uniform. The rotor $B$ is solid, moreover, or may be made of a thick tube, and its surface potential is not uniform and may be nowhere zero.

Consider any point $P$, Fig. 4 , on the

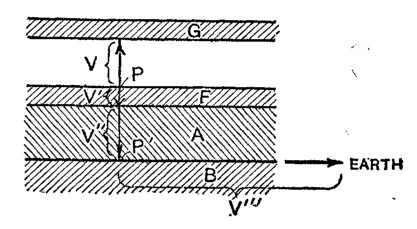

Fig. 4. outer surface of the cylinder $F$. Let the potential of $P$ be denoted by $v$, the voltage through $F$ radially inward by $v^{\prime}$, the voltage along the same radius through $A$ by $v^{\prime \prime}$, and the potential at $P^{\prime}$, the point of the rotor's surface on the same radius, by $v^{\prime \prime \prime}$. Then

$$
v=v^{\prime}+v^{\prime \prime}+v^{\prime \prime \prime}
$$

and the average value $V$ of $v$ over the surface of $F$ is equal to the sum of the average values $V^{\prime}, V^{\prime \prime}$, and $V^{\prime \prime \prime}$ of $v^{\prime}, v^{\prime \prime}$, and $v^{\prime \prime \prime}$. That is

$$
V=V^{\prime}+V^{\prime \prime}+V^{\prime \prime \prime} \text {. }
$$

Let $f$ denote the outward radial component of the motional intensity at any point of $A$ or $F$ distant $r$ from the axis, $e$ the outward radial component of the intensity of the electric field at the same point, $S$ the capacity the portion of the field whose tubes stretch between $B$ and $F$ would have if its dielectric were ether alone, and $S^{\prime}$ the capacity of the part of the field whose tubes stretch between $F$ and the conductors at zero potential, chiefly the tube $G$ and the screens $Q Q$. Also let $F$ and $E$ denote the average values of $f$ and $e$ over the cylinder of radius $r$, whose length, $l$, is equal to that of $A$ and $F$. Then, on the theory of Lorentz, 


$$
(K-\mathrm{I})(F+E) 2 \pi r l=4 \pi\left(S V^{\prime \prime}+S^{\prime} V\right) \cdot{ }^{1}
$$

For the total charge upon $F$ is zero; and therefore the flux to $F$ due to the electric displacement of the moving, or material, portion of the insulator $A$ is equal to the flux from $F$ in the ether and air.

Thus the average value $\Psi$ of the motional E.M.F. $\psi$ from $B$ to $F$ is

$$
\Psi=\int_{r_{1}}^{r_{2}} F d r=\frac{2\left(S V^{\prime \prime}+S^{\prime} V\right)}{(K-\mathrm{I}) l} \int_{r_{1}}^{r_{2}} \frac{d r}{r}-\int_{r_{1}}^{r_{2}} E d r .
$$

The extreme radii $r_{1}$ and $r_{2}$ are mean values; but the cylinders can be turned so true that their departures from uniformity in diameter can be neglected. If we write

$$
S^{\prime \prime \prime}=\frac{l}{2 \log r_{2} / r_{1}},
$$

i. e., the capacity $F A B$ would have if its dielectric were ether alone, and its field an entirely straight-line field between $B$ and $F$, and if we denote the average voltage in the conductors, viz., $V^{\prime}+V^{\prime \prime \prime}$, by $U$, (I 3 ) may be written

or

$$
\Psi=V-U+\frac{S(V-U)+S^{\prime} V}{(K-\mathrm{I}) S^{\prime \prime \prime}},
$$

$$
V=\frac{(K-\mathrm{I}) S^{\prime \prime \prime}(\Psi+U)+S U}{(K-\mathrm{I}) S^{\prime \prime \prime}+S+S^{\prime}} .
$$

If $S^{\prime \prime}$ denotes the actual capacity of the condenser $F A B$, so far as this depends on the tubes of displacement stretching between $F$ and $B$, then

$$
(K-\mathrm{I}) S^{\prime \prime \prime}+S=K S^{\prime \prime \prime}+\left(S-S^{\prime \prime \prime}\right)=S^{\prime \prime}
$$

very approximately. Also, in the apparatus used in this investigation,

$$
S-S^{\prime \prime \prime}=0
$$

with neglible error, on account of the smallness of the ratio of the thickness to the length of the cylindrical condenser and the presence of the screens $Q Q$. Hence the expression for $V$ may be written

$$
V=\left(\frac{K-\mathrm{I}}{K} \Psi+U\right) \frac{S^{\prime \prime}}{S^{\prime \prime}+S^{\prime}} .
$$

${ }^{1}$ Inasmuch as the voltages $V^{\prime}$ and $V^{\prime \prime}$ are not uniform the capacities involved differ slightly from $S$ and $S^{\prime}$. The differences are here neglected. 
Formulation of Equation for Experimental Test.

Calibration.

The quantity $V$ cannot be measured directly without an insulated sliding contact, which, unless in the form described near the end of this paper, introduces very great difficulties and should be avoided. Hence we proceed as follows:

The charge upon the outer coat of $F$, at the average potential $V$, is $S^{\prime} V$; and a charge very approximately $-S^{\prime} V$ exists on the inner surface and ends of the cylinder $G$. Some of the tubes from $F$ end on the screens $Q Q$, however, and some on the other earthed conductors, so that the charge on $G$ is not exactly $-S^{\prime} V$. If now $G$ is insulated and then connected with the electrometer, and if $F$ is earthed, an electrometer deflection $d$ will be produced such that

$$
C d=-S^{\prime} V=-\left(\frac{K-\mathbf{I}}{K} \Psi+U\right) \frac{S^{\prime \prime} S^{\prime}}{S^{\prime \prime}+S^{\prime}},
$$

where $C$ is a constant.

To use this equation and to simplify the experimental work we must proceed further as follows: First the metal cylinders $F$ and $G$ are connected together by the rod $J$, the wire $N$, and the keys, and charged to a common potential $V_{0}$, while $B$, with the other conductors, remains earthed. Owing to the presence of $G$, which now acts as a guard cylinder, the charge $q_{0}$ taken by $F$ is confined to its inner surface except close to the ends, and the electric field near the ends of $A$ is more nearly like that at the center than it would be if the tube $G$ were absent. The actual capacity of the condenser $F A B$ with this field is very approximately the capacity already denoted by $S^{\prime \prime}$, and but few tubes of displacement stretch between the ends of $F$ and the screens $Q Q$, owing to the field of the guard-tube $G$. Hence, very approximately,

$$
q_{0}=S^{\prime \prime} V_{0} .
$$

After the cylinders have become charged, $N$ is raised, thus insulating $F$ from $G$ and $J$, and then both $G$ and $J$ are earthed. The inner surface of $G$ has now received a charge $q^{\prime}$ given very approximately by the equation

$$
q^{\prime}=-q_{0} \frac{S^{\prime}}{S^{\prime \prime}+S^{\prime}}
$$


[VOL. XXVII.

The cylinder $G$ is now insulated and connected to the electrometer, and $F$ is earthed. The charge $q^{\prime}$ is distributed over the insulated system, and the electrometer gives a deflection $d_{0}$ proportional thereto by the constant $C$ of equation (20). Thus

$$
q^{\prime}=C d_{0}=-q_{0} \frac{S^{\prime}}{S^{\prime \prime}+S^{\prime}}=-V_{0} \frac{S^{\prime \prime} S^{\prime}}{S^{\prime \prime}+S^{\prime}} .
$$

Dividing the equation (20) for $C d$ by the equation (2I) for $C d_{0}$, and multiplying by $V_{0}$, we obtain

$$
\frac{d}{d_{0}} V_{0}=\frac{K-\mathrm{I}}{K} \Psi+U
$$

Let $I$ denote the current in the coil, $\tau$ the time of one revolution of the rotor, and $\bar{T}$ and $\bar{U}$ the values of $\Psi$ and $U$ when $I$ and $\tau$ are unity. Then

$$
\Psi=\bar{\Psi} \frac{I}{\tau} \quad \text { and } \quad U=\bar{U} \frac{I}{\tau}
$$

Thus equation (22) may be written

or

$$
V_{0} \frac{d}{d_{0}}=\left[\bar{\Psi} \frac{K-\mathrm{I}}{K}+\bar{U}\right]_{\tau}^{I}
$$

$$
V_{0} \frac{d}{d_{0}} \frac{\tau}{I}-\bar{U}=\bar{\Psi} \frac{K-\mathrm{I}}{K} \text {. }
$$

This equation will be satisfied by the experimental results if the ether is at rest. The quantity $\bar{T}$ is given by equation (4), $\bar{B}$, the average value, for a current of one ampère, of the axial induction, being substituted for $B$.

If the ether and matter move together with the same velocity, the equation

$$
V_{0} \frac{d}{d_{0}} \frac{\tau}{\bar{I}}-\bar{U}=\bar{T}
$$

will be satisfied. This assumes that the rotation takes place in vacuo, or that the surrounding air is not set into motion by the rotating parts. On the theory of Lorentz it is of no consequence whether the air moves or not, $K-\mathrm{I}$ for air being entirely neglible.

The experimental methods of determining all the quantities involved are described below. 
The Apparatus Used in the Principal Experiment.

A considerable portion of the apparatus was briefly described in explaining the general method used in the experiments. The bobbin on which the coil $C$, Fig. 3, was wound was made of a brass tube $D, 48.0 \mathrm{~cm}$. long, $16.5 \mathrm{~cm}$. external diameter, and $1.6 \mathrm{~mm}$. thick, and two thick brass rings about $30 \mathrm{~cm}$. external diameter and of internal diameter equal to the external diameter of the tube. One side of each ring was turned plane, and the rings were mounted and soldered with their true surfaces outward, parallel, and flush with the ends of the tube. The true surfaces were then perpendicular to the axis of the tube.

The brass tube $H$, with internal diameter I I. $8 \mathrm{~cm}$., $48.0 \mathrm{~cm}$. long, and $\mathrm{I} .2 \mathrm{~mm}$. thick, was made coaxial with $D$ by means of two circular brass rings fitting tightly between the tubes near the ends. The tubes and rings were heavily soldered together. Small brass tubes soldered through the rings near their tops permitted a stream of tap-water to flow, at the will of the observer, through the space between the brass tubes.

The coil $C$ contained nearly 300 lbs. of No. Io copper wire wound in two sections, each of approximately $26 \times 75$ turns. The sections were well insulated and screened from one another and from the bobbin. The coil was mounted in two heavy clamps with its axis horizontal in a north and south line. In Fig. 5, which is a diagram of the apparatus as seen from the S. end, corresponding to the right end of Fig. 3, one of the clamps is shown. $B$ and $C$ are heavy wooden blocks, cut out to fit the coil, and drawn together by brass bolts $D D$.

The bearings $E E$ were cast from the non-magnetic alloy known as "lumen" metal, between which and bronze the friction is very slight. These castings were planed on their inner surfaces and the central portions of their outer surfaces, and were drilled with $\frac{7}{8}$ in. holes, accurately perpendicular to the plane surfaces. They were then so mounted in the large brass rings by small steel screws that the centers of the holes were on the axis of the brass tubes already described. The central portions of the bearing castings were 3.2 cm. thick.

Three rotors were used in the course of the motional experiments. 
[VoI. XXVII.

The first was turned from a phosphor bronze casting, and was shaped much like $B$ in Fig. 3. The terminal portions were turned with great precision to fit the $\frac{7}{8}$ in. holes in the bearing castings $E E$. The central cylinder was also turned with great precision. Its length was $33.6 \mathrm{~cm}$., within $\frac{1}{15}$ per cent., and its mean diameter was $5.044 \mathrm{~cm}$. This mean was obtained from two readings at right angles on each of I 3 circles equally spaced along the cylinder, the average departure of a single reading from the mean being much less than $0.00 \mathrm{I} \mathrm{cm}$. The ebonite rings $P P$ were turned carefully, so that the possible longitudinal motion of the rotor was very slight. The middle of the central cylinder of the rotor was $23.5 \mathrm{~cm}$. from the $\mathrm{S}$. bearing, $0.5 \mathrm{~cm}$. from the center of the bobbin. At the $\mathrm{N}$. end of the rotor was a small cylindrical projection onto which was forced a brass cylinder. A large thread was turned in this to form a worm.

The second rotor was turned from a rod of Tobin bronze, which is far superior to phosphor bronze, with precision about the same as that of the first. The central cylinder had practically the same length as that of the first rotor, and a mean diameter nearly the same, viz., $5.045 \mathrm{~cm}$. The center of this cylinder, like that of the first rotor, was $23.5 \mathrm{~cm}$. from the $\mathrm{S}$. bearing when in position. A worm was cut directly in the end of the N. terminal cylinder, which was longer than that of the first rotor.

The third rotor was a modification of the first, and will be described in connection with the experiments in which it was used.

When in position, the worm at the end of the rotor geared with a brass worm-wheel having 100 teeth. Once every hundred revolutions of the rotor a pin projecting from this wheel closed an electric circuit including the electromagnet of a chronograph. This arrangement, together with a standard clock, enabled the rotor's speed to be determined with precision.

The induction tube, or guard cylinder $G$, was a brass tube 36.4 $\mathrm{cm}$. long, $8.70 \mathrm{~cm}$. in external diameter, and $0.08 \mathrm{~cm}$. thick.

The mechanism by which the wire $N$, connected with the $\operatorname{rod} J$, Fig. 3, was operated is shown in Fig. 5. One end of a brass spring $I$, fastened at the other end to a nail in the wooden clamp $B C$, is attached to the cross-piece $H$ near its upper end. To the same 
point of $H$ is attached one end of a cord $J$, which passes through a ring $M$ and is attached near its other end to a small brass weight $K$. Below the weight are three small wooden steps. The spring, cord, and steps are so adjusted, that when the weight is on the highest, or first step, the string is loose and the spring presses the wire $N$ (Fig. 3) gently against the tube $F$. When the weight is placed on the third step, $N$ is raised above the tube $G$, into, or nearly into, contact with $H$ (Fig. 3).

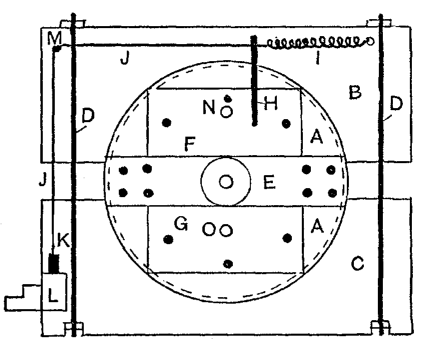

Fig. 5.

The essential parts of the keys I, 2, 3, 4 in the final work were constructed throughout of brass and amber. Keys 1, 2, and 3 were very nearly alike. The principle is the same as that of the electrometer key described by McLennan at the Philadelphia meeting of the American Physical Society (December, I904), but the keys described here are, in my opinion, much superior to McLennan's in insulation, simplicity of construction, and regularity in making and breaking contact. The construction of the keys is illustrated in Fig. $6 . \quad B$ is a rectangular block of amber about

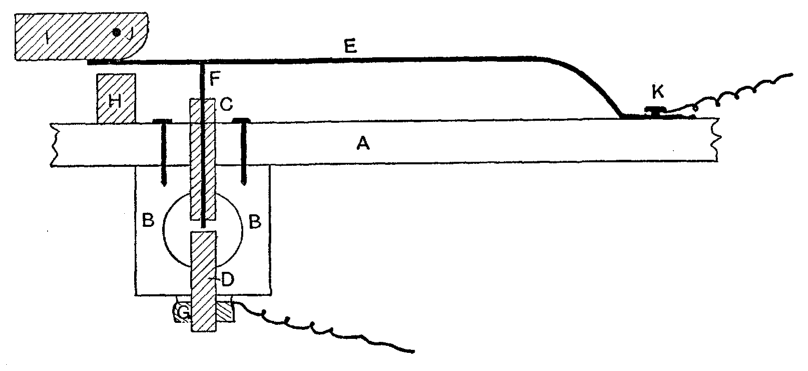

Fig. 6.

$2.5 \mathrm{~cm} . \times 2.5 \mathrm{~cm} . \times \mathrm{I} \mathrm{cm}$. A hole about $1.3 \mathrm{~cm}$. in diameter is drilled through the center of the block from face to face. Smaller holes are drilled and threaded to hold the threaded brass rods $C$ and $D$. The lower rod $D$ is left solid, with a flat top, andis provided below with one or more nuts and washers for electrical connections. The upper rod $C$ is drilled throughout its length to permit the 
[VoL. XXVII.

passage of a straight brass wire $F$, and the sharp edges of the hole are removed. The amber block is screwed beneath the top, or on one side, of a brass-lined box with the tube $C$ projecting through a hole, which may be small or large according to purposes of the key. The tube $C$ serves only as a guide to the wire $F$, and in some cases to complete the electric screening. The wire $F$ is soldered at right

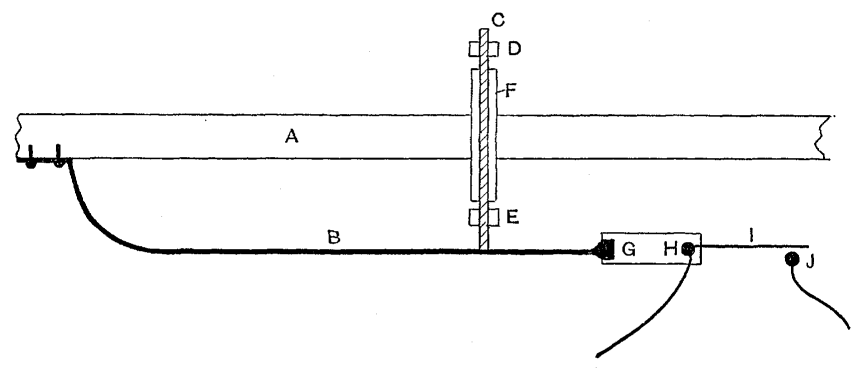

Fig. 7.

angles to a long brass strip $E$, which is bent as shown in the figure and screwed to the top of the box. The key is operated by the device HIJ, made of small pieces of wood and a small nail $J$. When $I$ is made horizontal, $F$ rises to its highest position, its lower end being then, if desired, within the tube $C$, and contact with $D$ is

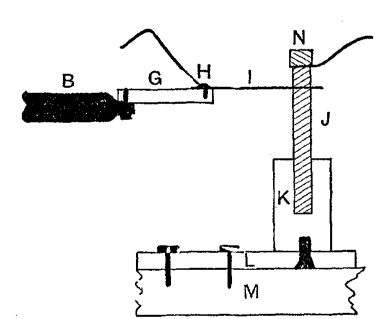

Fig. 8. broken. When $I$ is made vertical, $F$ is pressed down and makes contact with $D$. $I$ remains in the position in which it is placed. The actual amber blocks used in the experiments described here were nearly twice as thick as those described above and their central portions were cut down to a thickness of about $\mathrm{I} \mathrm{cm}$. This shape, however, is inferior, on account of both insulation and expense, to the simpler shape illustrated in Fig. 6.

The construction of key 4 is shown in Figs. 7 and 8. A brass strip $B$, similar to those used in keys $\mathrm{I}, 2$, and 3 , is screwed at one end to the under side of the top of the key box. The other end is screwed to one end of a small oblong block $G$ of amber. A fine spring brass wire $I$ is fastened to the other end of the amber block 
by means of a screw $H$, which connects $I$ to a fine brass wire running to the lower terminal of key I. When $B$ is lowered, the wire $I$ makes contact with a brass rod $J$, and hence, by a fine brass wire, with the lower terminal of the electrometer key 3. The $\operatorname{rod} J$ is supported by an amber block $K$ screwed to the brass plate $L$, itself screwed to one side of the key box $M$. The strip $B$ is raised and lowered by means of the brass $\operatorname{rod} C$, which is threaded and carries two brass nuts $D$ and $E$. The rod moves vertically through the brass tube $F$, passing through the top of the box, the distance through which it moves and the position it occupies when $I$ makes or breaks contact with $J$ being regulated finely by the nuts $D$ and $E$. Friction retains the rod $C$ in either position in which it is set.

The keys I, 2, 3, 4 were mounted in and on a brass-lined key box E, Fig. 9. The box contained also a commutator $A B C D$. It

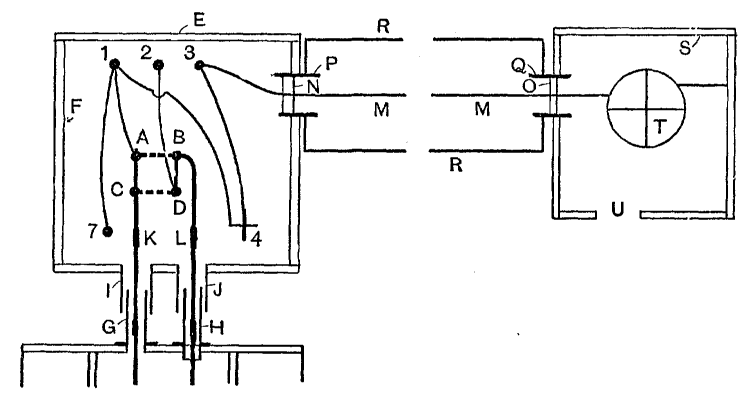

Fig. 9.

was made of a block of amber about $5 \mathrm{~cm} . \times 5 \mathrm{~cm} . \times 2.5 \mathrm{~cm}$., four brass posts $A, B, C, D$ screwed into the amber at the corners of a square, with two vertical saw cuts at right angles in the top of each, and two thin strips of brass by which the connections were made. It was mounted on a short pillar of brass, itself on a brass plate by which it was clamped to the base of the key box. This box was fastened to a heavy wall shelf which projected over the edge of the table supporting the great coil. The diagram shows roughly the relative positions of the keys, coil, etc., together with the electrical connections with the lower terminals of keys $\mathrm{I}, 2$, and 3 . The posts $C$ and $B$ of the commutator were connected by the jointed brass rods $K$ and $L$ with the brass tube $G$ and the rod $J$, of Fig. 3, 
respectively. The rod $K$ passed through a brass tube $I$, projecting through the side of the box, and a considerably smaller brass tube $G$, telescoping with $I$, screwed to the upper brass plate closing the space within the great coil. The space between $I$ and $G$ was partially filled with cotton wool. The joint was sometimes covered with tin foil. The rod $L$ passed through a similar arrangement of brass tubes, cotton, and tin foil. This arrangement prevented the transmission of any vibration from the motor and rotating apparatus to the key box, and at the same time formed a perfect electric screen and prevented the rapid escape, by this channel, of dry air within the box.

The electrometer was mounted in a brass-lined box $S$, Fig. 9 , screwed to a firm wall shelf. The boxes $E$ and $S$ were about $1.7 \mathrm{~m}$. apart and were connected by the brass tubes $P, Q$, and $R$. Narrow pieces of amber $N$ and $O$ were screwed in $P$ and $Q$ along diameters, and a fine brass wire $M$, connected at one end with the lower terminal of key 3 and at the other with the electrometer, was stretched, but not tightly, between them. The electrometer was an instrument of the Dolezalek type, with amberoid insulation, by the Cambridge Scientific Instrument Company. It was modified in the instrument shop, a charging key being added, and two of the quadrants being made adjustable radially for symmetry. The needle furnished with the instrument by the makers was injured and it was replaced by one made in this country, for the earlier observations. The needle was magnetic, a fact which was very troublesome until the instrument was removed to a considerable distance from the coil. Its behavior was improved by substituting a wooden rod for the aluminium rod and vane originally carrying the mirror. The method of experiment entirely eliminated any error due to the residual deflection of the needle by a magnetic field, as the fields were always destroyed many seconds before the deflection was read. The mirror was slightly convex, and gave excellent definition with the telescope and $2 \mathrm{~mm}$. scale used in the greater part of the work. In the experiments of 1908 an excellent new Cambridge needle, with the old mirror, was used. The telescope and scale were mounted on a pier, the scale being about $4.2 \mathrm{~m}$. from the mirror. Tenths of divisions were easily estimated with certainty on 
the $2 \mathrm{~mm}$. scale; on a $\mathrm{mm}$. scale used chiefly in the earlier part of the work they were estimated without great certainty. Several quartz fibers, varying in diameter from about $6 \mu$ to about $9 \mu$, were used in the course of the work. The needle was charged, through the key, to a potential of about 150 volts by means of a water battery.

The current which traversed the great coil in the principal experiment was supplied by a dynamo in the electrical engineering laboratory. By a simple arrangement of two switches the two sections in which the coil was wound could be connected either in parallel or in series. The terminals of this arrangement were connected through a reversing switch directly to the switchboard and dynamo mains. The capacity of the current meter, an excellent Siemens and Halske volt-ammeter, properly tested in this laboratory, was not sufficient to measure the total current when the two sections were in parallel; hence it was placed in one of the coil circuits through a reversing switch, and the resistances of the two coil circuits were made the same. The ammeter was on the pier with the telescope, so far from the coil as not to be affected by its field. Owing to the large amount of power consumed in the coil when its two sections were in parallel, many seconds elapsed after closing the circuit before the current reached an approximately steady value. In a single experiment the current was required for $3 \mathrm{O}^{\mathrm{s}}$, but its value had to be known with accuracy only at the end of this time, just before insulating the tube $G$ (see above); for only the part of the charge due to electric absorption could be affected by the value of the current prior to the instant mentioned. The ammeter was therefore read at this instant.

In the earlier experiments the rotor was usually driven by belt from a I h.p. direct current shunt-wound motor. The same dynamo supplied power to this motor and to the great coil - an objectionable arrangement, but the only one practicable. The speeds, however, were in almost all cases quite sufficiently constant. Different speeds were obtained by using different pulleys and an adjustable rheostat. In the later work a 2 h.p. alternating current motor was used, the constancy of whose speed left nothing to be desired. 
The Magnetic Field of the Great Coll.

In order to obtain the quantity $\bar{T}$ and one of the quantities constituting $\bar{U}$, viz., the value of $V^{\prime}$ for a current of I ampère in the coil, or $\bar{V}^{\prime}$, a study of the magnetic field throughout the region occupied by the rotating insulator and its metal cover was necessary. The well known method of the test coil, mutual inductance standard, and ballistic galvanometer was used, all necessary care being taken to secure more than adequate precision. The test coils were wound on true brass cylinders from No. 40 SSC. copper wire. Each coil contained from 40 to 42 turns, and was coaxial with the rotor when under experiment. Table I. gives the flux in electromagnetic C.G.S. units through the mean turn of each coil, for a current of I ampère in the great coil, as a function of its distance in $\mathrm{cm}$. from the $\mathrm{S}$. end of the bobbin. For each coil a smooth curve was plotted on a large scale between the flux and the distance. From each curve the flux through the mean turn of the corresponding coil was obtained for intervals corresponding to every half $\mathrm{cm}$. of the length of the central cylinder of the rotor; and from these and the necessary additional curve readings, corresponding to points near the ends of the central cylinder, the mean flux through the mean turn was calculated for the whole distance between the ends of the central cylinder. The mean flux thus

TABLE I.

Magnetic Field of Great Coil. July 25, 1907.

\begin{tabular}{c|c||c|c||c|c||c|c}
\hline \multicolumn{2}{c||}{ Coil x. } & \multicolumn{2}{c|}{ Coil 2. } & \multicolumn{2}{c|}{ Coil 3. } & \multicolumn{2}{c}{ Coil 4. } \\
\hline Distance. & Flux. & Distance. & Flux. & Distance. & Flux. & Distance. & Flux. \\
\hline 6.2 & 1418 & 6.2 & 1770 & 5.2 & 1989 & 4.2 & 2491 \\
7.2 & 1492 & 9.2 & 2007 & 9.2 & 2365 & 7.2 & 2926 \\
10.2 & 1652 & 12.2 & 2142 & 12.2 & 2560 & 10.2 & 3258 \\
13.2 & 1756 & 15.2 & 2225 & 15.2 & 2658 & 13.2 & 3476 \\
16.2 & 1824 & 18.2 & 2269 & 18.2 & 2704 & 16.2 & 3557 \\
19.2 & 1838 & 21.2 & 2276 & 21.2 & 2717 & 19.2 & 3588 \\
22.2 & 1839 & 24.2 & 2268 & 24.2 & 2698 & 22.2 & 3593 \\
25.2 & 1831 & 27.2 & 2255 & 27.2 & 2687 & 25.2 & 3582 \\
28.2 & 1817 & 30.2 & 2228 & 30.2 & 2657 & 28.2 & 3575 \\
31.2 & 1793 & 33.2 & 2178 & 33.2 & 2606 & 31.2 & 3518 \\
34.2 & 1732 & 36.2 & 2084 & 36.2 & 2473 & 34.2 & 3416 \\
37.2 & 1651 & 39.2 & 1932 & 39.2 & 2288 & 37.2 & 3232 \\
40.2 & 1496 & 42.2 & 1682 & 42.2 & 2008 & 40.2 & 2934 \\
\hline
\end{tabular}


determined for each coil is given in Table II. This table also gives the mean diameter of each coil and the ratio of the mean flux through its mean turn to the cross-section of this turn, $i$. $e$., the mean magnetic induction parallel to the axis of the rotor through the turn. The results show that the mean flux across a right section of the insulating cylinder, its coat, or the rotor, is proportional to the area of this section, and equal to that area $\times 88.65$ in C.G.S. electromagnetic units.

TABLE II.

\begin{tabular}{l|c|c|c|c}
\hline \multicolumn{1}{c|}{ No. of Test Coil. } & $\mathrm{I}$ & 2 & 3 & \multicolumn{1}{c}{4} \\
\hline Mean diameter of coil. & $5.009 \mathrm{~cm}$. & 5.571 & 6.081 & 7.011 \\
Mean flux through mean turn. & 1746 & 2162 & 2573 & 3425 \\
Mean induction through mean turn. & 88.6 & 88.7 & 88.6 & 88.7 \\
\hline
\end{tabular}

Mean induction through mean turns of all four coils $=\bar{B}=88.65$.

The Mean Potential of the Central Surface of the Rotor for a Current of I Ampère in the Great Coil.

Owing to lack of symmetry and to the extension of the bearing surfaces currents exist to some extent in the rotor. Hence the quantity sought cannot be obtained precisely from a knowledge of the magnetic field. An approximately correct value can be obtained by determining the mean magnetic flux through the tubular bearing surfaces experimentally by means of a suitable test coil, etc., and subtracting this from the mean magnetic flux across a right section of the central cylinder of the rotor, obtained from its diameter and Table II. Near the close of the work described here this was carefully done, and the value $1,6 r_{3}$ C.G.S. units obtained. This is nearly the same as the more nearly correct value found earlier by the following method:

The brass bearing $K$, Fig. 3, was replaced by a bearing of ebonite, and the rod $J J$ by a long brass rod of the same diameter marked in $\mathrm{cm}$. Fastened to the rod at a known point was a narrow strip of brass $A$ with its plane vertical and perpendicular to the rod. $A$ was kept pressed against the rotor by means of a cross-piece and a small weight, and could be made to touch the rotor at any desired distance from the $\mathrm{S}$. end of the bobbin. The rotor was driven very uniformly, and almost continuously through- 
[VOL. XXVII.

out a series of observations, by a storage battery, which furnished current at the same time to the great coil. The current was measured with the volt-ammeter already mentioned, and the potential $v^{\prime \prime \prime}$, or the voltage from the point of contact of $A$ and the rotor to the earthed bobbin, was measured with a D'Arsonval galvanometer,

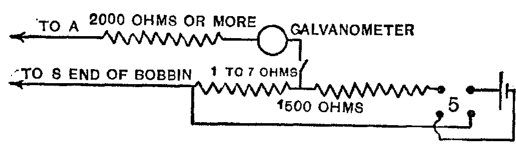

Fig. 10.

etc., the apparatus being arranged as in Fig. Io. The battery shown in the figure was of course used only for calibration purposes. Speeds were recorded automatically on the chronograph.

Two series of observations were taken on rotor $\mathrm{I}$. The resulting values of $\bar{v}^{\prime \prime \prime}$, or $v^{\prime \prime \prime}$ for a current of I ampère in the great coil and a rotor speed of I revolution per second, in C.G.S. units, are given as a function of the distance $D$ in $\mathrm{cm}$. from the $\mathrm{S}$. end of the bobbin in Table III. The average value of $\bar{v}^{\prime \prime \prime}$, or $\bar{V}^{\prime \prime \prime}$, for the central

TABLE III.

\begin{tabular}{|c|c|c|c|c|c|}
\hline \multicolumn{4}{|c|}{ First Rotor. June $17,1907}$. & \multirow{2}{*}{$\frac{\text { Second Rotor. }}{D}$} & December 3, 1907 . \\
\hline$D$ & $\begin{array}{c}\bar{v}^{\prime \prime \prime} \\
\text { First Series. }\end{array}$ & $\begin{array}{c}\overline{v^{\prime \prime \prime}} \\
\text { Second Series. }\end{array}$ & $\begin{array}{c}\overline{v^{\prime \prime \prime \prime}} \\
\text { Mean. }\end{array}$ & & $\bar{v}^{\prime \prime \prime}$ \\
\hline 7.6 & 1390 & 1385 & 1388 & 7.1 & 1372 \\
\hline 8.6 & 1444 & 1440 & 1442 & 8.2 & 1416 \\
\hline 10.6 & 1551 & 1544 & 1548 & 9.2 & 1479 \\
\hline 12.6 & 1615 & 1613 & 1614 & 11.2 & 1569 \\
\hline 14.6 & 1658 & 1662 & 1660 & 13.2 & 1629 \\
\hline 16.6 & 1690 & 1679 & 1684 & 15.2 & 1679 \\
\hline 18.6 & 1703 & 1701 & 1702 & 17.2 & 1703 \\
\hline 20.6 & 1702 & 1702 & 1702 & 19.2 & 1711 \\
\hline 22.6 & 1715 & 1713 & 1714 & 21.2 & 1714 \\
\hline 24.6 & 1702 & 1705 & 1704 & 23.2 & 1698 \\
\hline 26.6 & 1700 & 1700 & 1700 & 25.2 & 1703 \\
\hline 28.6 & 1687 & 1691 & 1689 & 27.2 & 1695 \\
\hline 30.6 & 1678 & 1673 & 1676 & 29.2 & 1694 \\
\hline 32.6 & 1643 & 1638 & 1640 & 31.2 & 1665 \\
\hline 34.6 & 1595 & 1603 & 1599 & 33.2 & 1635 \\
\hline 36.6 & 1541 & 1545 & 1543 & 35.2 & 1588 \\
\hline 38.6 & 1457 & 1470 & 1464 & 37.2 & 1523 \\
\hline 40.1 & 1336 & 1358 & 1347 & 39.2 & 1448 \\
\hline & & & & 40.2 & 1389 \\
\hline
\end{tabular}


surface of rotor I was I, 616 C.G.S. units, each series giving the same result. The results of a similar series of observations on rotor 2 are given in the same table. From this series $\bar{V}^{\prime \prime \prime}$ for rotor 2 is I,620 C.G.S. units. An earlier, but inferior, set, obtained under adverse conditions, gave 1,6 I 7 C.G.S. units. Within the limits of experimental error these values are all identical ; and as the differences between the diameters, lengths, and positions of the central surfaces of the two rotors were neglible, the mean of the first and second results, viz., $\bar{v}^{\prime \prime \prime}=$ I,6I 8 C.G.S. units, or 0.000016 I 8 volt, will be adopted for both rotors.

It was also found by experiment that the voltage between the two ends of the great bobbin was less than one sixth per cent. of the potential of the center of the central surface of the rotor.

\section{Determination of the Dielectric Constants.}

To determine the dielectric constant of the insulator $A$, the $\operatorname{rod} J$ was connected with the lower terminal of key I, and the tube $G$ with that of key 2 , Fig. I I, the change from the arrangement used in the experiment proper being made by means of the commutator $A B C D$ of Fig. 9 . Also the lower terminal of key I was connected to the "charge," or lower, terminal $A$ of a Kempe key 6, the

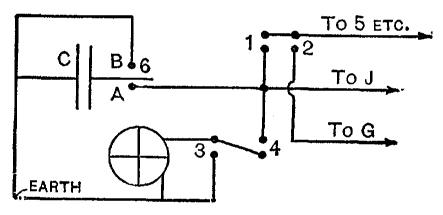

Fig. 11 . upper terminal $B$ of which was earthed. The lever of the key was connected with one armature of a standard mica condenser $C$, whose other armature was earthed.

In the determination of a dielectric constant two series of operations were necessary. (I) The resistance $R$, Fig. 3, was given a considerable value $\mathrm{R}_{1}$. Initially keys $\mathrm{I}, 2$, and 3 were closed, $N$ down, 4 and 5 open, and the lever of 6 up. Then, in succession, $(a) 5$ was closed, (b) $N$ was raised, $(c) 5$ was opened, $(d)$ I was opened, $(e) 4$ was closed, $(f)$ the lever of 6 was lowered, $(g) 3$ was opened, (h) $N$ was lowered, and the electrometer scale reading was taken. The process was repeated with the commutator 5 reversed, and the double deflection $d_{1}$ was obtained. In each of these processes the condenser $F A B$ was first charged to a voltage $V_{1}=R_{1} I$ ( $I$ being 
[VOL. XXVII.

the constant current in the circuit $R S T$ ). The field of this condenser, surrounded by the guard tube $G$ at the same potential as its outer coat, was essentially a straight-line field confined to the dielectric $A$. Then the conductor $F$ was connected to the insulated terminal of the standard condenser $C$, and the combination was then connected with the electrometer, $G$ and all other conductors being earthed.

(2) The resistance $R$ was given a much smaller value $R_{2}$, while the total resistance $R+S$ was kept the same as in (I). Initially I, 2, and 3 were closed, 4 and 5 open, $N$ down, and the lever of 6 down. Then, in succession, $(a)$ the lever of 6 was thrown to " insulate," (b) 5 was closed, $(c)$ the lever of 6 was lowered, and $(d)$ then immediately raised to "insulate," $(e) 5$ was opened, $(f)$ I was opened, $(g) 4$ was closed, $(h) 3$ was opened, $(i)$ the lever of 6 was lowered, and the electrometer reading was taken. The process was then repeated with the commutator 5 reversed, and the double deflection $d_{2}$ was obtained. In each of these processes the standard condenser was first charged to a voltage $V_{2}=R_{2} I$, and its insulated terminal then connected to the conductor $F$, all the conductors at the end of process (2) being connected precisely as at the end of process (I).

The double deflections of the electrometer in (I) and (2) are proportional to the charges on the insulated conductors. The charge in (I) is very approximately $S^{\prime \prime} V_{1}$. The charge in (2) is $S_{2} V_{2}$, if $S_{2}$ denotes the capacity of the standard condenser. Thus

or

$$
\frac{d_{1}}{d_{2}}=\frac{S^{\prime \prime} V}{S_{2}} \frac{S_{2}^{\prime \prime} R_{1}}{S_{2} R_{2}}
$$

$$
S^{\prime \prime}=S_{2} \frac{d_{1}}{d_{2}} \frac{R_{2}}{R_{1}}
$$

from which $S^{\prime \prime}$ can be readily determined. The dielectric constant $K$ can then be obtained from $S^{\prime \prime}$ and the dimensions of the cylinder $A$. If $r_{1}$ and $r_{2}$ are the internal and external radii of this cylinder, and $l$ its length, we have

$$
K=S^{\prime \prime} \frac{2 \log r_{2} / r_{1}}{l}
$$


The capacity $S^{\prime \prime}$ is slightly greater than that of the straight-line field Hence $K$ as determined above will be slightly too large. An error in $K$, however, makes a much smaller error in $K-\mathrm{I} / K$, the quantity with which we are concerned, since $d / d K[(K-\mathrm{I}) / K]=\mathrm{I} / K^{2}$.

The condenser used in the earlier experiments in sulphur, ebonite, and rosin, was the 0.02 M.F. division of an Elliott I M.F. mica condenser. The capacity of this division was compared with that of each higher division, from 0.05 M.F. to 0.50 M.F., by charging each to a voltage inversely proportional to its nominal capacity, and measuring the resulting throw on discharging through a ballistic galvanometer. The throw produced by the 0.02 M.F. division was $4.79 \mathrm{~cm}$., which is just equal to the mean of the throws produced by the other divisions.

In order to secure higher insulation than could readily be obtained with the Elliott condenser, with external insulation of ebonite and paraffin, it was replaced, in the later work, by a condenser constructed according to my design by Messrs. Leeds and Northrup. This is a mica condenser with air and amber external insulation. The terminals of the armatures are insulated by amber pillars, petticoated at the bottom, and fastened through the top of a small brass box. This condenser also failed to insulate sufficiently under conditions prevalent here; but it was made to insulate excellently by perforating the brass box with numerous holes, inserting all but the top in a larger paraffin-soaked wooden box whose bottom was covered with calcium chloride, and sealing up with beeswax. To increase the insulation still further, the condenser was ordinarily kept, while in use, within a large box heated to a temperature considerably higher than that of the room. The capacity of this condenser was certified by the makers to be 0.02 M.F., according to their own standard, within one fourth per cent. It did not differ by as much as one sixth per cent. from that of the Elliott condenser previously used.

The key 6 used in the earlier work was a Kempe key in ebonite and brass by Elliott. For the later work this key was modified in the instrument shop of this laboratory. The ebonite was replaced throughout by amber and brass, the insulation of amber being much superior to that of ebonite.

Connection between key 6 and key I was made by fine brass 
[VOL. XXVII.

wires $G$ and $H$ and the other apparatus shown in Fig. I 2. The brass tube $A$ passed through a hole in the top of the key box, and

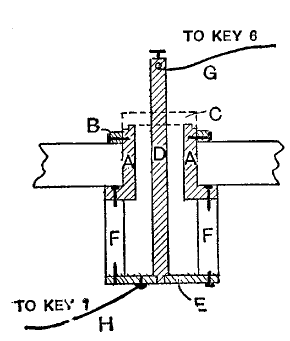

Fig. 12. was held in position by a small ring $B$. It held in position a tube of amber $F F$, to the bottom of which was screwed a brass plate $E$. During experiments on capacity, a slender brass binding post $D$ was kept screwed into the middle of the plate $E$. Except when capacity measurements were in progress, the rod $D$ was removed and the cylinder $A$ was covered with a brass cap $C$.

The First Experiments on Sulphur.

The sulphur used for the first cylinder which was successfully prepared was of the grade known as "washed sulphur." A rough cylinder of this material was cast in a cylindrical mold on the first bronze rotor, and this cylinder was accurately turned up on a lathe. It was covered with a thin coat of brass in the following manner, at the suggestion of Professor Stratton and Mr. Lange, of the National Bureau of Standards, accidents having interfered with the success of the electroplating process used later in coating a number of other cylinders with copper, and with another electrolytic process. A very uniform brass tube, whose internal diameter was about the diameter desired for the sulphur cylinder, not yet turned, was pounded onto an accurately turned cylinder of steel, prepared for the purpose. The average departure of 13 diameters of this cylinder from their mean was much less than $0.00 \mathrm{I} \mathrm{cm}$. The steel cylinder was then mounted in a lathe, and the brass coat was turned down until about $0.025 \mathrm{~cm}$. thick. The brass coat was then heated and slipped off the steel cylinder. The sulphur cylinder was turned to a diameter about $0.002 \mathrm{~cm}$. less than that of the steel. The brass tube was then forced onto the sulphur cylinder. In this process the rotor and sulphur cylinder were bent, but they were very approximately straightened by Mr. Lange, with great skill, in a heavy drill press. The rotor was then mounted in a lathe, the brass tube and sulphur cylinder were cut off at the proper points, and the brass tube was turned down until its mean external diameter 
was $6.832 \mathrm{~cm}$. The precision of the turning was as great as in the case of the sulphur cylinder, whose mean diameter, obtained from 26 properly spaced readings, was $6.802 \mathrm{~cm}$., the average departure of a single reading from the mean being much less than $0.00 \mathrm{I} \mathrm{cm}$. The difference between $6.832 \mathrm{~cm}$. and $6.802 \mathrm{~cm}$. would give 0.015 $\mathrm{cm}$. as the thickness of the brass coat. After the experiments were completed this thickness was studied more carefully. The brass coat was removed and cut into I I strips, each about $3 \mathrm{~cm}$. wide. The thickness of each of these strips, which were about $21.4 \mathrm{~cm}$. long, was measured at 7 points about $3 \mathrm{~cm}$. apart. The mean thickness obtained in this way was $0.0156 \mathrm{~cm}$. Each strip gave nearly the same mean, the variations being about $0.00 \mathrm{I} \mathrm{cm}$. But the mean thickness along one generating line of the cylinder was 0.OI I cm. (the minimum), and that along an almost diametrically opposite generating line was $0.022 \mathrm{~cm}$. (the maximum). Thus the axis of the outer surface of the coat was parallel to that of the inner surface, the rotor, etc., but was slightly displaced laterally therefrom. The departures from the theoretical conditions of the experiments could have had no appreciable effect on the results even had the work been of far greater precision.

The dielectric constant of the sulphur was measured by the process described above. The manner in which this constant depended upon the time of charging was first investigated by repeating process (I) for a number of different times of charging, from I second to 40 seconds. The capacities and dielectric constants were approximately proportional to the electrometer throws given in the following table :

$\begin{array}{lccccc}\text { Time in seconds : } & 1 & 10 & 20 & 30 & 40 \\ \text { Mean electrometer throw : } & 11.25 & 11.36 & 11.38 & 11.43 & 11.42\end{array}$

The results show that absorption is practically complete after $30^{\mathrm{s}}$ at most. This fact being known, the dielectric constant was determined by a series of the processes (I) and (2), performed alternately to eliminate a possible change in the electrometer's sensibility, the time of charging in ( $\mathrm{I}$ ) being $30^{\mathrm{s}}$. The values of $R_{1}$ and $R_{2}$ were $5,000 \mathrm{ohms}$ and $50 \mathrm{ohms}$, respectively. The results are given in the following table : 


$\begin{array}{llllcl}\text { Process : } & (2) & (1) & (2) & (1) & (2) \\ \text { Mean throw : } & 8.80 & 10.70 & 8.80 & 10.69 & 8.81\end{array}$

The ratio of the mean throw for process (I) to that for process (2) is I.2 I 5 , that of $R_{1}$ to $R_{2}$, IOO. Together with the dimensions of the sulphur cylinder, these data give for the dielectric constant

$$
K=3.89 \text { for the time of charging } 30^{\mathrm{s}} \text {. }
$$

The process of "calibration" was carried out as follows: Initially keys I, 2, 3 were closed, $N$ down (in contact with $F$ ), and 4 and 5 open. Then, in succession, (a) 5 was closed, (b) $N$ raised, (c) 5 opened, $(d)$ I opened, $(e) 4$ closed, $(f) 3$ opened, $(g) N$ lowered, and $(h)$ the electrometer scale reading taken. The process was then repeated with 5 reversed, and again with 5 in its original position. The double deflection $d_{0}$ corresponding to the voltage $V_{0}$ along $R$ was obtained. In this process, all the operations, with a few exceptions, were performed in quick succession. In $(a), 5$ was kept closed for $30^{\mathrm{s}}$; in $(f) 3$ was opened $30^{\mathrm{s}}$ after $N$ was raised in (b), except in the earlier experiments, when this interval was $20^{\mathrm{s}}$; and the electrometer reading in $(h)$ was ordinarily taken $70^{\mathrm{s}}$ after the opening of 3 in $(f)$. The $20^{\mathrm{s}}$ or $30^{\mathrm{s}}$ interval between $(b)$ and $(f)$ was determined on from a series of experiments in which this interval was varied from $5^{\mathrm{s}}$ to $30^{\mathrm{s}}$. The electrometer throws increased from I I. 66 for $5^{\mathrm{s}}$ to I 1.76 for I $^{\mathrm{s}}$ to $30^{\mathrm{s}}$.

In the experiment proper, keys I and 5 were initially open, 2, 3, 4 closed, $N$ down, the rotor at rest, and the current in the coil zero. Then, in succession, $N$ was raised, the motor was started and brought to full speed, the coil circuit was closed, the current was determined, 3 was opened $30^{\mathrm{S}}$ after the coil circuit was closed, the coil circuit was broken, the motor was stopped, $N$ was lowered, and the electrometer scale reading was taken, ordinarilly $70^{\mathrm{s}}$ after 3 was opened. The process was repeated with the coil current reversed, and again with the current in the original direction. The double deflection $d$ corresponding to the coil current $I$ and the period $\tau$ of the rotor was determined. All operations were performed in quick succession, except as indicated.

In both sets of experiments the double deflection of the electrometer was obtained by taking the difference between the second 
reading and the mean of the first and third. In most cases four or more readings were taken instead of three, deflections being alternately in opposite directions. In such cases the same mode of combination was followed. Thus, in the case of four readings, the first and third were combined with the second, and the second and fourth with the third; and the mean of the two double deflections was taken. All observations were taken at regular intervals, the times being recorded. The quotient of the current and the period of the rotor was treated like the electrometer deflection in combining observations. In case a single observation had to be rejected, the two preceding and the two following were combined. A few observations were rejected because the wire $N$ was accidentally left or put in contact with the tube $F$ while the rotor was in motion, which caused fine particles of metal to fly off from $N$ and $F$ to $G$, or because particles flew off for other reasons. In this way large deflections, entirely different from those due to the effect in question, were produced.

As the sensibility of the electrometer did not remain constant throughout a series of observations, the "calibration" was performed a number of times during each series of observations, for a known value of $V_{0}$; and from these observations a curve was plotted between $d_{0}$ and the time, from which $d_{0}$ was obtained for any time for which it was needed. In no case was the average departure of the experimental value of $d_{0}$ from the value given by the curve less than about one half per cent. or greater than about three fourths per cent.

The mean values of $\tau, I, d / d_{0} \cdot V_{0}, I / \tau$ and $d / d_{0} \cdot V_{0} \cdot \tau / I$ for each set of observations are given in Table IV. The table also gives the ranges of $d$ and $d_{0}$. The values of the quantities in the seventh and eighth columns were calculated as indicated above, and not from the values of $\tau$ and $I$ given in the table, which are simply the mean values for the sets, inserted to show the approximate values of the quantities in the different experiments. Owing to the large departures of the single observations of $d$ from their mean, these mean values of $\tau$ and $I$ could, of course, have been used in the calculations without serious effect. The mean value of $d / d_{0} \cdot V_{0} \cdot \tau / I$ given at the foot of the last column was obtained by multiplying 
the numbers in each of the two columns immediately preceding by the number of observations in the set, adding in two columns, and dividing the sums of the numbers in the first column by the sum of those in the second.

TABLE IV.

First Sulphur Cylinder. June 10-14, 1907.

\begin{tabular}{|c|c|c|c|c|c|c|c|c|}
\hline $\begin{array}{l}\text { No. of } \\
\text { Set. }\end{array}$ & $\begin{array}{c}\text { No. of } \\
\text { Observa- } \\
\text { tions } \\
\text { in Set. }\end{array}$ & $\begin{array}{l}\tau \times \text { I0o in } \\
\text { Seconds. }\end{array}$ & $\begin{array}{c}I \text { in } \\
\text { Amperes. }\end{array}$ & $d$ in $\mathrm{cm}$ & $d_{0}$ in $\mathrm{cm}$ & $\begin{array}{c}d l d_{0} \cdot V_{0} \\
\text { in } \\
\text { Volts. }\end{array}$ & $I / \tau$ & $d\left|d_{0} \cdot \nu_{0} \cdot \tau\right| I$ \\
\hline 1 & 7 & 1.435 & 12.15 & & & 0.0252 & 845 & 0.0000298 \\
\hline 2 & 6 & 1.446 & 12.21 & & & 231 & 844 & 274 \\
\hline 3 & 8 & 1.455 & 12.00 & & & 234 & 828 & 283 \\
\hline 4 & 8 & 1.457 & 11.93 & & & 206 & 819 & 252 \\
\hline 5 & 8 & 1.474 & 21.38 & From & From & 395 & 1453 & 272 \\
\hline 6 & 4 & 1.472 & 20.63 & 1.58 & 6.24 & 381 & 1399 & 272 \\
\hline 7 & 8 & 1.442 & 12.48 & to & to & 225 & 865 & 260 \\
\hline 8 & 4 & 1.447 & 12.18 & 6.92 & 7.56 & 226 & 843 & 268 \\
\hline 9 & 4 & 1.488 & 21.60 & & & 383 & 1450 & 264 \\
\hline 10 & 6 & 1.471 & 21.06 & & & 384 & 1431 & 268 \\
\hline 11 & 6 & 1.344 & 11.77 & & & 212 & 887 & 239 \\
\hline 12 & 6 & 3.35 & 21.71 & & & 172 & 647 & 266 \\
\hline 13 & 6 & 3.72 & 20.14 & & & 136 & 543 & 250 \\
\hline 14 & 4 & 3.77 & 21.28 & & & 140 & 568 & 246 \\
\hline 15 & 4 & 2.37 & 11.50 & & & 144 & 490 & 294 \\
\hline 16 & 4 & 1.368 & 20.42 & & & 368 & 1496 & 246 \\
\hline 17 & 10 & 1.288 & 11.27 & & & 227 & 878 & 259 \\
\hline 18 & 4 & 1.305 & 20.10 & & & 408 & 1542 & 265 \\
\hline 19 & 4 & 2.57 & 11.20 & & & 109 & 430 & 253 \\
\hline 20 & 4 & 2.91 & 19.98 & & & 162 & 690 & 235 \\
\hline \multicolumn{9}{|c|}{ Weighted mean $0.0000264 \frac{1}{2}$} \\
\hline
\end{tabular}

From the data given above, the value of $\Psi(K-\mathrm{I}) / K$ for the sulphur cylinder is $0.00001450 \times 2.89 / 3.89$ volt $=0.0000108$ volt, and the value of $\bar{U}$ is 0.000016 I 8 volt +0.00000030 volt $=0.0000-$ I648 volt. Hence the mean value of $d / d_{0} \cdot V_{0} \cdot \tau / I-\bar{U}$ is 0.0000 Ioo volt, which differs from $\Psi(K-\mathrm{I}) / K$ by between 7 per cent. and 8 per cent. This discrepancy is less, however, than the average departure from their mean of the values of $d / d_{0} \cdot V_{0} \cdot \tau_{/}^{\prime} I$ for the separate sets, which is about $\mathrm{I} 3$ per cent. The theory of Lorentz is thus confirmed within the limits of the experimental error; while the discrepancy between the experimental results and those to be 
expected on the ether motion theory is over 45 parts in 145 , or over 3 I per cent.

The constancy of the last column in the table shows that $d / d_{0} \cdot V_{0}-U$ is proportional to $I$ and inversely proportional to $\tau$, as required by all theories. The same thing is shown by Fig. I3, in

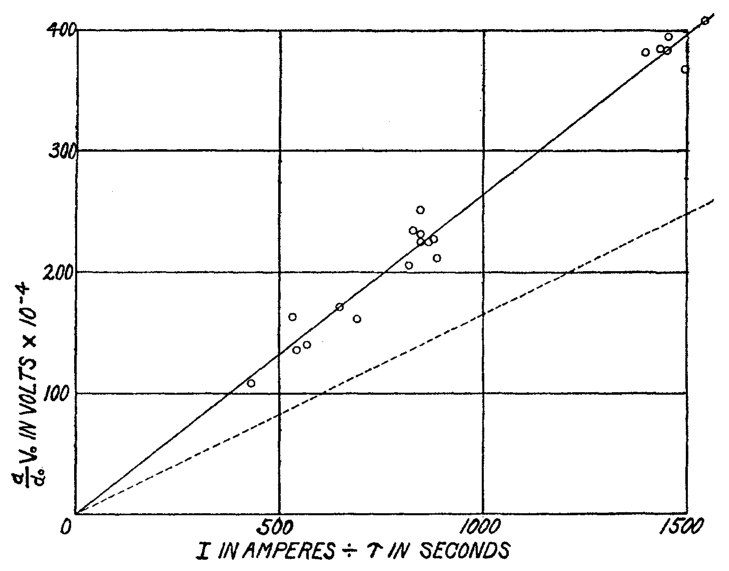

Fig. 13.

which the continuous line gives the relation between $d / d_{0} \cdot V_{0}$ and $I / \tau$, and the dotted line that between $U$ and $I / \tau$. The full line is so drawn that the ratio of the ordinate of any point to its abscissa is the weighted mean $0.0000264 \frac{1}{2}$, and the separate sets of observations are indicated in the usual way.

In order to obtain sufficient insulation the room in which the experiments were performed was kept at a temperature considerably higher than that outside, and bottles of sulphuric acid were kept inside the key box and the electrometer box. For the same purpose, and also to remove dust from the chamber in which the rotor moved, a slow stream of air was driven into the inlet $I$ through a calcium chloride bottle and a cotton filter. This was kept up day and night by a hand bellows operated by a small motor.

The First Experiments on Rosin.

A rough cylinder of rosin, of one of the lighter varieties, was cast on rotor 2 and was then turned up accurately in a lathe. Its length, like that of the central cylinder of the rotor, was $33.6 \mathrm{~cm}$. 
within $\frac{1}{16}$ per cent. and its mean diameter was $6.65 \mathrm{I} \mathrm{cm}$. from $\mathrm{I} 2$ measurements equally spaced along the cylinder, the average departure from the mean being $0.002 \mathrm{~cm}$. The rosin cylinder, before being cut to the proper length, was covered with a thin sheet of copper by the well-known electrolytic process used in electrotyping. The rosin was first rubbed with powdered graphite. A thin sheet of copper was then deposited by sprinkling the surface with iron filings and rotating it in a solution of copper sulphate. After being washed, the copper coat was thickened by being made the kathode in a copper sulphate electrolytic cell whose anode was a circular cylinder of copper nearly coaxial with the rotor. After being electroplated, the cylinder was treated with emery paper and sand paper in a lathe and its ends trued to the rotor. After the experiments the copper coat was stripped off and weighed. From the weight and area of the sheet and the density of copper the mean thickness was found to be $0.025 \mathrm{~cm}$.

TABLE V.

First Rosin Cylinder. July 23-24, 1907.

\begin{tabular}{c|c|c|c|c|c|c}
\hline $\begin{array}{c}\text { No. of } \\
\text { Set. }\end{array}$ & $\begin{array}{c}\text { No. of } \\
\text { Observa- } \\
\text { tions } \\
\text { in Set. }\end{array}$ & $\begin{array}{c}\tau \times \text { roo } \\
\text { in Seconds. }\end{array}$ & $\begin{array}{c}I \text { in } \\
\text { Amperes. }\end{array}$ & $\begin{array}{r}d l d_{0} \cdot V_{0} \\
\text { in Volts. }\end{array}$ & $I / \tau$. & $d^{\prime} d_{0} \cdot V_{0} \cdot \tau / I$. \\
\hline 1 & 6 & 1.433 & 20.91 & 0.0352 & 1453 & 0.0000242 \\
2 & 6 & 1.385 & 11.17 & 196 & 806 & 244 \\
3 & 7 & 1.212 & 11.26 & 234 & 931 & 240 \\
4 & 6 & 1.231 & 20.22 & 405 & 1641 & 247 \\
5 & 4 & 1.503 & 12.06 & 177 & 801 & 220 \\
6 & 4 & 1.420 & 11.91 & 189 & 839 & 225 \\
7 & 5 & 1.463 & 21.49 & 356 & 1472 & 242 \\
8 & 10 & 1.446 & 21.16 & 350 & 1458 & 240 \\
9 & 4 & 1.187 & 20.00 & 426 & 1696 & 251 \\
\hline
\end{tabular}

The dielectric constant of the rosin was determined in the same manner as that of the sulphur. Three sets of measurements each gave this constant as 2.99 for a charging time of 30 seconds.

The experiments on the motion of the rosin in a magnetic field was conducted in nearly the same manner as the corresponding experiments on sulphur. But instead of series of "calibration" ex- 
periments, a series of determinations of the voltage sensibility was made on each of the two observation days; and the ratio of the "calibration" deflection to the voltage deflection for the same E.M.F. was determined once for all from a special series of observations. Also, the bellows was not operated, and heat was not supplied to the room, for a number of hours during the night. The cylinder was heated in the rotation chamber before the experiments began, the temperature being that of tap-water during the experiments.

The results of the observations are given in Table V., where the same symbols are used as in Table IV.

From the data given in this table and earlier, $\bar{U}$ is 0.0000 I $66 \frac{1}{2}$ volt, and the mean value of $d / d_{0} \cdot V_{0} \cdot \tau / I-\bar{U}$ is 0.0000076 volt, with an

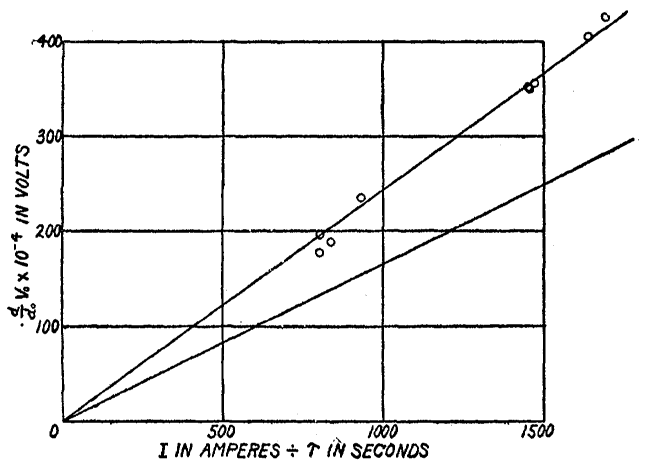

Fig. 14.

average departure from the mean of nearly ro per cent. The quantity $\bar{\Psi}$ is 0.0000 I 308 volt, and $\bar{\Psi}(K-\mathrm{I})_{i}^{\prime} K$ is 0.000087 volt. The discrepancy between these experimental results and Lorentz's theory is thus I I parts in 87 , or nearly I 3 per cent., and that between the experimental results and the alternative theory is 55 parts in $\mathrm{I} 3 \mathrm{I}$, or 42 per cent. The experimental error is large, but the results are again decidedly in favor of the first-named theory.

Like the experiments on sulphur, those on rosin show a direct proportionality between $d / d_{0} \cdot V_{0}-U$ and the quotient $I / \tau$, as demanded by all theories. This is shown by the table, as also by the graphs of Fig. 14. The upper line shows the relation between $d / d_{0} \cdot V_{0}$ and $I / \tau$, and the lower line that between $U$ and $I / \tau$. 
The First Experiments on Ebonite.

From a thick ebonite tube five hollow cylinders were turned, the sum of their lengths being made about equal to the length of the central cylinder of rotor $\mathrm{I}$ and their internal diameters about equal to the diameter of the same cylinder. These cylinders were forced into position on the rotor and the outer surface of the long ebonite cylinder thus formed was turned down to a mean diameter of 6.716 $\mathrm{cm}$. This surface was then covered with a thin layer of shell-lac and a coat of silver leaf, after which the whole was heated inside the great coil. The dielectric constant of the ebonite was determined, and found to be 3.90 . The variation of this constant with time of charging was also investigated. It was approximately proportional to the mean electrometer throws in the following table:

$\begin{array}{lcccc}\text { Time of charging : } & 10^{\mathrm{s}} & 20^{\mathrm{s}} & 30^{\mathrm{s}} & 40^{\mathrm{s}} \\ \text { Mean throw : } & 21.45 & 21.78 & 21.84 & 21.88\end{array}$

Experiments on the effect of the motion of the ebonite in the magnetic field of the great coil were begun, but the effect was found to be completely masked by another and much larger effect, independent of the magnetic field and the direction of rotation, and proportional to the square of the frequency of rotation. The effect was too great and too irregular to permit of its elimination in the magnetic experiments by taking observations with both directions of the magnetic field. The effect was such as would be produced by a radial E.M.F. acting outward in the ebonite during the rotation only and proportional to the square of the frequency, as if there were a centrifugal differential displacement of the two kinds of electrons.

The results of the first two series of systematic observations, during which the mean temperature was about $33^{\circ} \mathrm{C}$., are given in Table VI.

TABLE VI.

Ebonite Cylinder.

\begin{tabular}{|c|c|c|c|c|c|c|c|c|c|}
\hline \multicolumn{5}{|c|}{ June $25,1907}$. & \multicolumn{5}{|c|}{ June 26 , rgo7. } \\
\hline Time. & $S$ & $\tau \times 100$ & $S / \tau^{2}$ & $D$ & Time. & $S$ & $\tau \times 100$ & $S / \tau^{2}$ & $D$ \\
\hline $3^{\text {h }} 40^{\mathrm{m}}$ & 12.85 & $5.02^{s}$ & $51 \times 10^{2}$ & 1.46 & $10^{\mathrm{h}} 17^{\mathrm{m}}$ & 9.58 & 1.924 & $259 \times 10^{2}$ & 7.75 \\
\hline 356 & 12.76 & 3.92 & 83 & 2.37 & $11 \quad 25$ & 9.41 & 1.228 & 624 & 21.0 \\
\hline 14 & 12.71 & 3.60 & 98 & 2.82 & $\begin{array}{ll}11 & 47\end{array}$ & 9.35 & 1.204 & 645 & 21.7 \\
\hline 436 & 12.65 & 2.16 & 271 & 9.27 & $2 \quad 18$ & 8.91 & 0.743 & 1614 & 50.4 \\
\hline $4 \quad 55$ & 12.61 & 1.91 & 346 & 11.97 & 240 & 8.84 & 0.861 & 1193 & 41.2 \\
\hline
\end{tabular}


The relation between the deflection $(D)$ and the ratio of the electrometer's sensibility $(S)$ to the square of the period $(\tau)$ of the rotor is shown graphically in Fig. I 5. This effect was studied on sev-

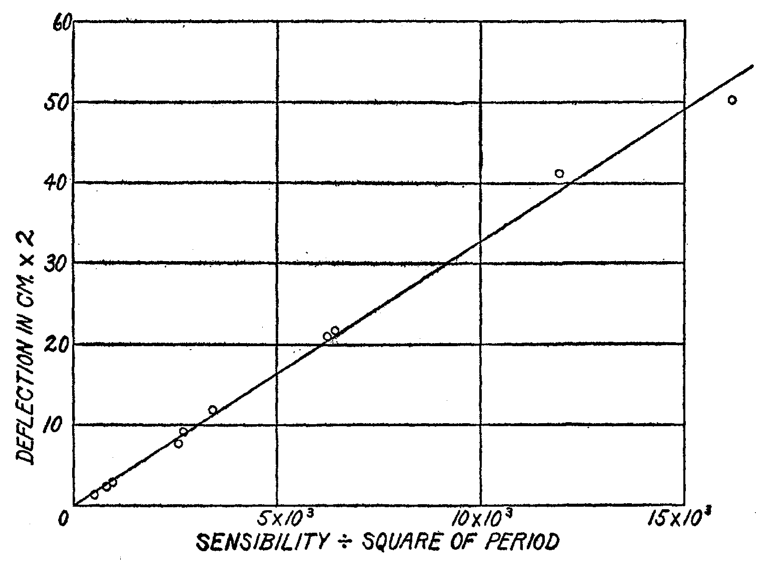

Fig. 15.

eral days. Its magnitude appeared to depend on the temperature of the ebonite and on other factors, no one of which has yet been sufficiently investigated.

The effect did not exist with the rotor alone, and it did not exist, in a later series of experiments, either with the rotor alone, or when an insulating cylinder of the usual dimensions but completely covered with copper in contact with the rotor was rotated.

\section{Experiments on Paraffin and Spermaceti.}

A cylinder of pure hard paraffin was cast on one of the rotors turned true on a lathe, and covered with a copper coat by the electrolytic process already described. The electric absorption of the paraffin cylinder, as tested with an electroscope, was so great, however, that no further experiments were made with it. Doubtless a cylinder free from absorption could have been produced, had we been able to cast under pressure. But, having no facilities for this, we were unable, in several attempts, to get a homogeneous cylinder free from numerous cavities.

Attempts to cast on a rotor cylinders of paraffin and of spermaceti, at once homogeneous and firmly adherent to the rotor, having 
[VoL. XXVII.

failed, a mixture consisting of equal parts, by weight, of the two was tried. This also failed. A rough adherent cylinder of the mixture was finally formed by a dipping process similar to that by which the old fashioned tallow candle was formed. This was turned up and coated with copper in the usual way. The absorption of this cylinder, also, was very great. Nevertheless it would have been examined for the electrical effect in question, though without hope of quantitative results of value, had not it been injured by accident just as the experiments were starting.

\section{Later ExPERiments with Sulphur.}

A second cylinder of sulphur was cast on rotor 2, turned down to a mean diameter of about $6.934 \mathrm{~cm}$., covered with a layer of paraffin $0.006 \mathrm{~cm}$. thick, then covered with a coat of copper 0.046 $\mathrm{cm}$. thick, and then turned down at the ends until the length of the cylinder was $33.6 \mathrm{~cm}$. The object of the paraffin coat was to prevent the penetration of the copper sulphate solution, used in electroplating, into the sulphur cylinder.

The capacity $S^{\prime \prime}$ of the cylinder was found to be 207 E.S. units for a charging time of $30^{\mathrm{s}}$. This gives the dielectric constant (calculated on the assumption of a homogeneous dielectric) about 3.94 for the time $30^{\mathrm{s}}$. The absorption was investigated as in the case of the other sulphur cylinder. The capacity for different times of charging was approximately proportional to the throws in the following table:

$\begin{array}{lccccc}\text { Time of charging : } & 1^{\mathrm{s}} & 10^{\mathrm{s}} & 20^{\mathrm{s}} & 30^{\mathrm{s}} & 50^{\mathrm{s}} \\ \text { Mean throw : } & 11.63 & 11.73 & 11.76 & 11.84 & 11.85\end{array}$

No experiments on the electric displacement in the cylinder due to its motion in a magnetic field were practicable, as this effect, at speeds giving sufficient sensibility, was completely masked by an apparently "centrifugal" E.M.F. similar to that found in the experiments on ebonite, but in the opposite direction, the E.M.F. being directed inward, and more constant in time. The results of the observations taken on the last day on which experiments were made with the cylinder are given in Table VII. Each deflection $(D)$ given is the mean from ten readings, and all deflections are reduced to the same electrometer sensibility. The observations made on 
TABLE VII.

Speed.
37.3 r.p.s.
70.5 “"
96.9 “

April 20, 1908.

Deflection in $\mathrm{cm} . \times 2$.

earlier days were consistent with those given in the table, and many of them much better. The deflections given in the table are small for the reason that a stiff fiber was used while obtaining them.

The observations given in Table VII. are plotted in Fig. I6. The relation between the deflection and the square of the speed is seen to be linear. The deflections are far greater than those due to the effect which alone was expected.

The effect of heat on the non-magnetic effect was tried with a speed of 37 r.p.s. Two sets of observations were taken at the mean temperature $25^{\circ} \mathrm{C}$., and between them a similar set at $4 \mathrm{I}^{\circ} \mathrm{C}$. The former gave the mean deflection 5.5, with an average departure from the mean of 0.3 ; while the latter gave the mean deflection 6.7 , with an average departure from the mean of between 0.6 and 0.7 .

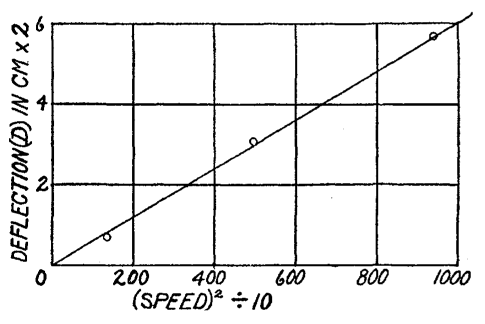

Fig. 16.

While the nature of the effect observed precluded the possibility of its being due to the presence of dust, it seemed worth while to try the effect of blowing the dust out of the region surrounding the rotor more thoroughly than had been done. This was done by a rotary blower, which sent a strong stream of air into and through the rotation chamber through a filter of cotton. But the effect persisted as before. The cylinder was finally destroyed to make room for the rosin cylinder described below.

The sulphur cylinder was cast on March I 8 , and the last experiments, given in the table, were performed on April 20. The experiments on the first sulphur cylinder were made nearly a year after the cylinder was cast and coated.

A few weeks after the completion of the experiments just de- 
scribed another cylinder was cast, from roll sulphur, and was turned up and coated with paraffin and a very thin deposit of copper. The cylinder failed to insulate, however, and it was found that the acid had penetrated to the rotor through a small defect in the paraffin coat. Lack of time prevented further work on sulphur.

\section{Later Experiments with Rosin.}

Several attempts were made to cast and turn cylinders of brittle rosins, but without success. A cylinder was then prepared from rosin of the grade known as "extra water-white," which gave no difficulty in casting and turning. A much harder rosin could have been turned with ease. This cylinder was turned down to a mean diameter of $6.834 \mathrm{~cm}$., the average departure from this mean of $\mathrm{I} 7$ readings properly spaced being less than $0.00 \mathrm{I} \mathrm{cm}$. This cylinder was coated with copper in the usual way. While the coat was very thin, the cylinder became slightly indented on one side, owing to its softness, but not sufficiently to injure it appreciably for the purposes of the experiments. The mean final external diameter of the copper coat was $6.912 \mathrm{~cm}$. As the copper coat, after being treated with files and sand-paper, was not very uniform, 68 uniformly spaced readings of the diameter were taken. The average departure of a single measurement from the mean was $0.003 \mathrm{~cm}$. The length of the copper cylinder was $33.6 \mathrm{~cm}$., and that of the rosin a fraction of a mm. less, the ends of the rosin being made somewhat irregular by fusing them with a blow-pipe to prevent fine particles cracking off and flying away during the rotation experiments. The dielectric constant of the rosin for a charging time of $30^{\mathrm{s}}$ was 3.22 . The manner in which this constant varied with the time of charging, and also the manner in which the calibration deflection depended upon the time of charging and the interval elapsing between the end of the charging and the opening of key 3 are shown in the following table. The observations were made like the ordinary "calibration" observations, except that throws were taken instead of steady deflections.

The experiments on this rosin cylinder were performed under better conditions than those of 1907. Arrangements were made for heating the air within the key box and the tube connecting it 


\begin{tabular}{c|c|c|c}
\hline Time. & Time of Charging. & $\begin{array}{c}\text { Interval between } \\
\text { Charging and } \\
\text { Opening Key 3. }\end{array}$ & $\begin{array}{c}\text { Mean Electrometer } \\
\text { Throw. }\end{array}$ \\
\cline { 2 - 4 } $4^{\mathrm{h}} 2^{\mathrm{m}}$ & $30^{\mathrm{s}}$ & $20^{\mathrm{s}}$ & 5.21 \\
12 & 30 & 40 & $5.22 \frac{1}{2}$ \\
21 & 30 & 20 & 5.20 \\
34 & 5 & 20 & 5.13 \\
40 & 20 & 20 & $5.18 \frac{1}{2}$ \\
48 & 40 & 20 & $5.20 \frac{1}{2}$ \\
57 & 30 & 20 & 5.19 \\
\hline
\end{tabular}

with the electrometer box to a temperature considerably above the room temperature, and the insulation was further increased by inserting vessels of $\mathrm{CaCl}_{2}$ in the boxes in addition to sulphuric acid. The room was not heated. Also, a rotary blower, already mentioned, was kindly placed at my disposal by my colleague Professor B. P. Caldwell. This blower was arranged to send a strong current of air into the region surrounding the rotor through two $\mathrm{CaCl}_{2}$ bottles in series, one very large, the other smaller, and a thick layer of tight cotton wool. This removed dust very completely, and increased the insulation considerably. The blower was not kept going continuously, but was used from time to time. Also, as stated above, the direct current motor used in the earlier observations was replaced by an alternating current motor, whose speed, under the existing conditions, was much more nearly constant. The quartz fiber used in the electrometer was stiffer than that used in the earlier work, but the sensibility was entirely sufficient.

TABLE VIII.

Second Rosin Cylinder. June 8, 1908.

\begin{tabular}{c|c|c|c|c|r|r|r}
\hline \hline $\begin{array}{c}\text { No. of } \\
\text { Set. }\end{array}$ & $\begin{array}{c}\text { No. of } \\
\text { observa- } \\
\text { tions } \\
\text { in Set. }\end{array}$ & $\begin{array}{c}\tau \times \text { roo in } \\
\text { Seconds. }\end{array}$ & $\begin{array}{c}I \text { in } \\
\text { Amperes. }\end{array}$ & $\begin{array}{c}d \text { in } \\
\mathbf{c m} \times \times 2 .\end{array}$ & $d l d_{0}$. & $\begin{array}{r}d l d_{0} \cdot V_{0} \\
\text { in Volts. }\end{array}$ & $d_{i} d_{0} \cdot V_{0} \cdot \tau / I$. \\
\hline 1 & 7 & 1.021 & 21.40 & 2.44 & 0.565 & 0.0556 & 0.0000265 \\
2 & 10 & 1.021 & 11.42 & 1.274 & .296 & 292 & 261 \\
3 & 8 & 1.016 & 11.72 & 1.36 & .319 & 314 & 272 \\
4 & 8 & 1.020 & 20.74 & 2.38 & .565 & 557 & 274 \\
5 & 7 & 1.772 & 20.16 & 1.28 & .306 & 301 & 265 \\
6 & 10 & 1.769 & 10.96 & 0.673 & .162 & 159 & 257 \\
7 & 8 & 1.019 & 18.74 & 2.03 & .490 & 483 & 262 \\
\hline
\end{tabular}


[VoL. XXVII.

The results of the rotation observations made on June 8 are given in Table VIII., where the symbols have the same meanings as in earlier tables. Earlier observations, consistent with these but made before the best conditions were attained, were not reduced.

The method of observation was nearly identical with that used in the case of the first sulphur cylinder. The time elapsing between the opening of key 3 and the reading of the electrometer was shorter, owing to the quicker fiber and needle used.

Six determinations of the "calibration" deflection were made during the day. The average departure of a single determination from the value given by the curve was about 2 parts in 425 .

From the data contained in Table VIII. and in what precedes, $\bar{U}$ is 0.00001618 volt +0.00000075 volt $=0.0000169$ volt; the mean value of $d / d_{0} \cdot V_{0} \cdot \tau / I-\bar{U}$ is 0.0000097 volt; and the value of $\bar{T}(K-\mathrm{I}) / K$ is $0.00001480 \times 2.22 / 3.22$ volt $=0.0000102$ volt. Thus the discrepancy between the last two quantities, or the discrepancy between the experimental results and those called for by Lorentz's theory, is 5 parts in IO2, or about 5 per cent., with an average departure from the mean of a trifle over 5 per cent.; while the discrepancy between the experimental results and those to be expected on the alternative theory is $5 \mathrm{I}$ parts in 148 , over 34 per cent.

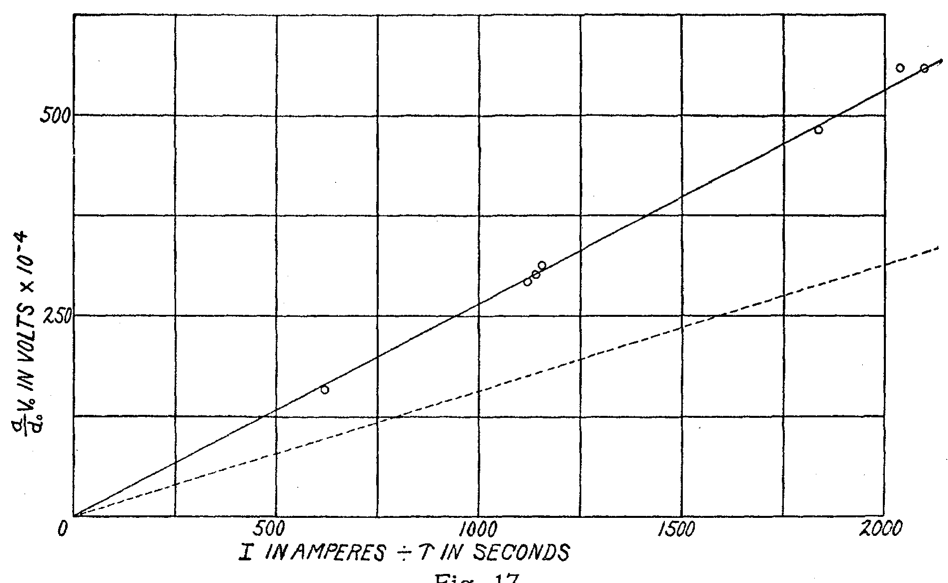

Fig. 17.

The experimental values of $d / d_{0} \cdot V_{0}$ and $I / \tau$ are plotted in Fig. I 7, the full straight line being drawn for the weighted mean. The 
relation between the quantities is linear, as required by all theories. The dotted straight line shows the relation between $U$ and $I / \tau$.

\section{Later Experiments with Ebonite.}

Rotor I had been slightly injured in preparing the first sulphur cylinder. It was therefore turned down slightly and electroplated with copper. The bearings were then turned down to the same diameter as before, and the central cylinder was turned to the diameter $5.106 \mathrm{~cm}$., the mean of six readings about equally spaced along its length, the average departure from the mean being $0.00 \mathrm{I} \mathrm{cm}$. The ebonite cylinders used in the previous experiments were thoroughly cleaned, then heated considerably above the room temperature and forced onto the rotor hot, with thin layers of paraffin between them. The surface was then treated, in the lathe, with files and sand-paper until its mean diameter was $6.608 \mathrm{~cm}$. The surface was not very true, the average departure from the mean of 32 properly spaced readings, in two planes, being $0.004 \mathrm{~cm}$. The cylinder was then coated with copper by the process already described. The mean diameter of the copper coat, from 32 properly spaced measurements, was $6.7 \mathrm{I} \mathrm{I} \mathrm{cm}$., the average departure of a single measurement from the mean being $0.003 \mathrm{~cm}$. It was found, however, that the cylinder failed to insulate, copper sulphate having penetrated some of the spaces between the separate ebonite cylinders. A similar failure of insulation resulted when $\mathrm{V}$-shaped grooves, a few $\mathrm{mm}$. deep, were cut into the junctions and filled carefully with hard shell-lac before: electroplating. Finally, the grooves were cut out, rings of ebonite about $2.5 \mathrm{~mm}$. thick being removed from the two cylinders at each junction, and the spaces were carefully filled with sealing wax. The surface was covered with a thin coat of Venice turpentine to make the carbon adhere better, and then electroplated as before. At first this cylinder insulated excellently, but later the insulation broke down. Two of the ceiling-wax rings were then cut out, and excellent insulation was found to be restored. Thin strips of metal were then soldered across the gaps to unite the different parts of the copper coat electrically. The total length of the ebonite and sealingwax was now $32.5 \mathrm{~cm}$., while the length of the central cylinder of the rotor was $33.6 \mathrm{~cm}$. as before. 
The capacity of the cylinder was determined as 297 E.S. units for $30^{\mathrm{s}}$ as the time of charging. This gives as dielectric constant the enormous value $4.7 \mathrm{I}$, a straight-line field and a homogeneous dielectric being assumed as in the cases of the more nearly perfect cylinders. The capacity as determined was so great as to arouse strong suspicion that copper sulphate had penetrated between some of the ebonite cylinders from one of the armatures to within a small distance of the other. Hence, after the completion of the experiments described below, the remaining sealing-wax rings were cut out and the capacity was again determined, on two occasions. It had changed but slightly. As a further check, the capacity of the Leeds \& Northrup condenser was again compared with that of the Elliott condenser, and was found to have remained unchanged. In the earlier experiments the dielectric constant of the same ebonite had been found to be 3.90 . In these experiments the ebonite cylinders were on a rotor of diameter $5.044 \mathrm{~cm}$., with little strain; while in the later experiments they were highly heated and shrunk onto a rotor of diameter $5.106 \mathrm{~cm}$., so that they were under considerable strain when at normal temperature. They had, moreover, been heated several times in the interim.

TABLE IX.

Ebonite Cylinder. June 12, 1908.

\begin{tabular}{r|r|r|r|r|r|r|r|r}
\hline $\begin{array}{c}\text { No. of } \\
\text { Set. }\end{array}$ & $\begin{array}{c}\text { No. of } \\
\text { observa- } \\
\text { tions } \\
\text { in Set. }\end{array}$ & $\begin{array}{c}\tau \times \text { roo in } \\
\text { Seconds. }\end{array}$ & $\begin{array}{c}I \text { in } \\
\text { Amperes. }\end{array}$ & $\begin{array}{c}d \text { in cm. } \\
\times 2 .\end{array}$ & $d l d_{0}$. & $\begin{array}{l}d \mid d_{0} \cdot V_{0} \\
\text { n } \\
\text { volts. }\end{array}$ & $I \mid \tau$. & $d\left|d_{0} \cdot V_{0} \cdot \tau\right| I$. \\
\hline 1 & 6 & 1.041 & 21.44 & 2.33 & 0.560 & 0.0551 & 2059 & 0.0000268 \\
2 & 6 & 1.036 & 11.72 & 1.20 & .290 & 285 & 1131 & 252 \\
3 & 6 & 1.785 & 20.74 & 1.25 & .310 & 305 & 1162 & 263 \\
4 & 6 & 1.784 & 11.10 & 0.66 & .165 & 163 & 622 & 262 \\
5 & 6 & 1.786 & 19.48 & 1.21 & .305 & 300 & 1091 & 275 \\
6 & 7 & 1.048 & 10.88 & 1.12 & .284 & 279 & 1038 & 269 \\
\hline
\end{tabular}

The results of the rotation experiments, which were conducted very nearly like those upon the second rosin cylinder, with more use of the blower, are given in Table IX. During the observation day 4 sets of "calibration" deflections were obtained. The last set, as 
well as the shortly preceding and last set of rotation experiments, was rejected for the reason that the insulation was becoming poor. The average departure of the deflections obtained from one of the calibration sets from the value given by the curve was about I part in 400 .

The value of $\bar{\Psi}$, calculated on the assumption that the mean induction $\bar{B}$ was 88.65 , as in the case of cylinders equal in length to the rotor, was $0.0000 \mathrm{I} 225 \mathrm{volt}$, and the value of $\bar{\Psi}(K-\mathrm{r})_{i} / K$ was 0.00000965 volt. The value of $\bar{U}$, calculated from the value of $\bar{U}$ for rotors $I$ and 2, the difference between their radius and that of the rotor carrying the ebonite, and the mean induction $\bar{B}$ used above, together with the cross-section of the copper coat $F$, was 0.0000 I 757 volt. The errors here introduced by the small departures from theo-

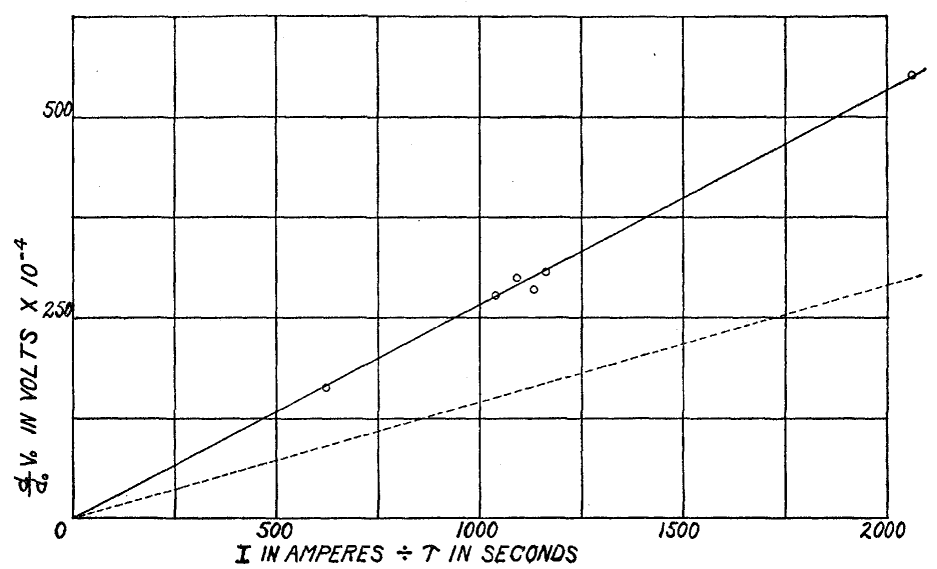

Fig. 18.

retical conditions are negligible in comparison with those introduced in the rotation experiments. The weighted mean value of $d / d_{0} \cdot V_{0} \cdot \tau / I$ was 0.00002654 volt. The difference between this quantity and $\bar{U}$ is 0.00000897 volt, which should equal 0.00000965 volt, the value of $\bar{\Psi}(K-\mathrm{I}) / K$, on Lorentz's theory. The discrepancy is 7 per cent., with an average departure from the mean of the same magnitude. The discrepancy between the experimental results and those to be expected on the ether motion theory is 33 parts in 123 , or 27 per cent. 
The experimental results for $d / d_{0} \cdot V_{0}$ and $I_{i} \tau$ are plotted in Fig. I8. The full straight line is drawn for the weighted mean. The relation is linear, as with the other insulators. The dotted line gives the relation between $U$ and $I / \tau$.

The observations do not show the curious "centrifugal" effect described in connection with the first experiments on ebonite. In the later experiments the temperature of the ebonite was that of the tap-water, about $28^{\circ} \mathrm{C}$.

\section{WiLSON'S EXPERIMENTS.}

The theory of Wilson's experiments, already referred to, can be developed without difficulty from equation (I 5 ) above.

Suppose the induction tube $G$ to be removed, the rod $J J$ to be connected to the insulated quadrants of the electrometer, as well as to the insulated armature of a standard condenser, and the wire $N$ to be in permanent sliding contact with the metal tube $F$.

Let $S^{\mathrm{IV}}$ denote the capacity of the tubes of displacement stretching between the conductor $F$ and the earthed conductors, the rotor being excepted; and $S^{\mathrm{V}}$ the capacity of the tubes stretching between that part of the insulated system which is always at rest, viz., the wire $N$, the rod $J J$, etc., and the earth. Let $V^{\mathrm{v}}$ denote the potential of the insulated electrometer quadrants, which is equal to that of the wire $N$ and the part of the tube $F$ in contact therewith, when the rotor is in motion in the magnetic field. Then, in place of equation (I 5), we have

$$
\Psi=V-U+\frac{S(V-U)+S^{\mathrm{IV}} V+S^{\mathrm{v}} V^{\mathrm{v}}}{(K-\mathrm{I}) S^{\prime \prime \prime}} .
$$

If we write $V^{\mathrm{V}}-V=V^{\mathrm{IV}}$, and eliminate $V$, this equation and ( $\mathrm{I} 7$ ) give

$$
V^{\mathrm{v}}=\frac{(K-\mathrm{I}) S^{\prime \prime \prime} \Psi+S^{\prime \prime}\left(U+V^{\mathrm{IV}}\right)+S^{\mathrm{IV}} V^{\mathrm{IV}}}{S^{\prime \prime}+S^{\mathrm{IV}}+S^{\mathrm{v}}} .
$$

The electrometer gives a deflection $d$ proportional to $V^{\mathrm{v}}$, by a constant $B$. Thus

$$
V^{\mathrm{v}}=B d \text {. }
$$

If now the insulated system, all at rest, is given the charge $q_{0}$, it 
will come to such a potential $V_{0}$, and the electrometer will give such a deflection $d_{0}$, that

$$
V_{0}=B d_{0}=\frac{q_{0}}{S^{\prime \prime}+S^{\mathrm{IV}}+S^{\overline{\mathrm{v}}}} .
$$

From equations (27), (28), and (29), we obtain

or

$$
q_{0} \frac{d}{d_{0}}=\left[(K-\mathrm{I}) S^{\prime \prime \prime} \Psi+S^{\prime \prime}\left(U+V^{\mathrm{Iv}}\right)+S^{\mathrm{Iv}} V^{\mathrm{IV}}\right]
$$

$$
q_{0} \frac{d}{d_{0}}=\left[(K-\mathrm{r}) S^{\prime \prime \prime} \bar{T}+S^{\prime \prime}\left(\bar{U}+\bar{V}^{\mathrm{IV}}\right)+S^{\mathrm{IV}} \bar{V}^{\mathrm{IV}}\right] \frac{I}{\tau},
$$

which is the complete approximate formula for Wilson's experiments according to the theory of Lorentz. On the ether motion theory, $K$ - I must be replaced by $K$, the formulas derived from (26) by writing $K$ for $K-\mathrm{I}$ and omitting $S(V-U)$, being

$$
q_{0} \frac{d}{d_{0}}=\left[K S^{\prime \prime \prime}\left(\bar{\Psi}+\bar{U}+\bar{V}^{\mathrm{IV}}\right)+S^{\mathrm{IV}} \bar{V}^{\mathrm{IV}}\right] \frac{I}{\tau} .
$$

In these experiments a contact piece, corresponding to the wire $N$, touched the metal coat of the rotating cylinder at its center. The rotor was covered with a thin insulating tube, and this was covered with a tube of brass. This tube was earthed near one end of the insulating cylinder under experiment, which it carried. This construction doubtless offered but little difficulty in the case of the small ebonite cylinder which alone was investigated by Wilson; but in such experiments as those described in this paper it would have introduced considerable difficulties. This construction gives a small value of $\bar{U}$; but in reducing $\bar{U}$ there is no advantage, as this quantity is easily determined with great precision.

The theory of his experiment, as given by Wilson with the assistance of Professor Larmor, is partially incorrect. Equation (30) may be written

$$
q_{0} \frac{d}{d_{0}} \frac{\tau}{I}-S^{\prime \prime}\left(\bar{U}+\bar{V}^{\mathrm{IV}}\right)-S^{\mathrm{rv}} \bar{V}^{\mathrm{IV}}=\frac{K-\mathrm{I}}{K} \cdot K S^{\prime \prime \prime} \bar{T} .
$$

Instead of the capacity $K S^{\prime \prime \prime}$ in the second member of this equation, Wilson has $S^{\prime \prime}$. His other terms correspond to those given in 
the equation, although they are obtained in a very different way. Wilson's value of the first member of the equation is $12.74 \times 1 \mathrm{IO}^{-7}$ E.S. unit, while his value of the second member, with $S^{\prime \prime}$ incorrectly in place of $K S^{\prime \prime \prime}$ is $12.58 \times 1 \mathrm{I}^{-7} \mathrm{E}$.S. unit, the discrepancy being about I.3 per cent. In Wilson's work the value of $S^{\prime \prime}$ was 25.4 E.S. units and that of $K S^{\prime \prime \prime}$ was 24.3 E.S. units. If we correct the second member of $(32)$, writing as above $K S^{\prime \prime \prime}$. instead of $S^{\prime \prime}$, its value becomes $\mathrm{I} 2.04 \times \mathrm{IO}^{-7} \mathrm{E}$.S. unit, which is nearly 6 per cent. less than the experimental value of the first member, viz., I 2.74 E.S. units. On the ether motion theory, the second member must be replaced by $K S^{\prime \prime \prime} \Psi$, which is $16.74 \times 10^{-7}$ E.S. unit. The discrepancy between Wilson's results and this theory is thus 4 parts in 16.7 , or about 24 per cent.

Some time ago attention was called ${ }^{1}$ by me to another error in Wilson's theory, which, however, did not affect his experimental work or calculations, but only the interpretation of his results. The electromotive force $\Psi$ does not differ on the theory of Lorentz from its value on the ether motion theory, nor on either theory does it differ in conductors and insulators.

In the abstracts, already published, of a portion of this paper it was stated that in the third term of the second member of $(30)$ Wilson had $S^{\mathrm{IV}}+S^{\mathrm{V}}$, and that neither of these quantities had been separately determined, which made it impossible to say what was the discrepancy between his results and those called for by the theory of Lorentz. This statement I deeply regret, as it is not correct. It was due to a curious and inexcusable misunderstanding of a line in Wilson's paper (1. 19, p. I35, 1. c.).

A serious defect of Wilson's method lies in the insulated sliding contact with the inevitable abrasion and convection of charged particles from the brush and the coat of the rotating insulator. This defect can be eliminated by surrounding the rotating cylinder and brush with a second cylinder electrically connected with the brush

${ }^{1}$ Roy. Soc. Proceedings, I905. This note was sent to the Royal Society by Lord Rayleigh at my request that this be done if he agreed with me that the note should be published in the Proceedings; but the technical communication was made by Professor Larmor, who wished to add a note in reply. To one who has read the two notes and the early part of the theoretical work in this paper, I do not think any further statement is necessary to justify my position. 
and electrometer. The second cylinder should be longer than the first, as in the method described in this paper. In this case the modification would also eliminate any error due to friction between the initial coat of the insulating cylinder and dust in the air around it. For the algebraic sum of the charges developed at the contact or by friction with the dust is zero, and they would all be developed and retained within practically a closed hollow conductor. The same modification would also eliminate the term $S^{\text {IV }} V^{\text {IV }}$ from the formula.

\section{Conclusion.}

The apparatus used in the investigation described in this paper could be modified in a few hours to operate by the method just suggested, and some experiments will possibly be made in this way next fall. In the fall $I$ hope also to investigate a few cylinders by the method already used under still better conditions. The irregularities left in the case of the last experiments on rosin and ebonite are probably due in some way to imperfection of insulation, that of the insulating cylinder especially; and the insulation can be still further improved by making the apparatus much more nearly air tight. The insulation of a cylinder, after remaining in the bobbin all night with tap-water flowing through the jacket, may appear most excellent when tested with an electroscope after charging to a high voltage ; and yet, unless great irregularities are to result, it must be much improved when the low voltage calibration and rotation experiments are to be performed. The trouble is not due principally to leakage of the low voltage charges normally produced in the course of the experiments, but to the charging up of the insulated conductors owing to the voltaic electromotive forces between them and the earthed conductors, which are many times greater than the normally developed electromotive forces to be measured. These effects are greatly reduced by improving the insulation, and are largely eliminated by the methods of observation used. Their practically complete elimination can doubtless be effected by the method suggested.

The curious electromotive force developed by the mere rotation of certain insulators I hope also to investigate further.

Nearly all of the apparatus built especially for this investigation 
was constructed with great skill and patience by Mr. Tudor T. Hall, mechanician in this laboratory. To him I am also indebted for much other mechanical assistance, as well as for help in designing apparatus. A part of the instrumental work was skillfully done by the mechanicians, Messrs. Lange, Volz and Mann, of the laboratory of the National Bureau of Standards in Washington. In this laboratory, through the courtesy of Professor S. W. Stratton, Director of the Bureau, the apparatus was first set up, owing to the fact that power and other necessities were not available in my own laboratory in the summer of 1906. Although a severe illness of my assistant compelled me to desist from experimental work in Washington before I had fairly begun, I am much indebted for many kindnesses to Professor Stratton and his associates, who placed their splendid facilities freely at my disposal. The work has been completed with great difficulty, owing to exceptionally heavy pedagogical duties and other circumstances not necessary to mention here. Throughout the experimental work I have been assisted in the most faithful and efficient manner by Mrs. Barnett, to whom I am under further obligations for assistance in computing and for important suggestions.

Physical Laboratory, Tulane University of Louisiana, NeW Orleans, July 24, IgO8. 